\title{
Chemical Constituents in the Leaves of Vateria indica
}

\author{
Tetsuro Ito, ${ }^{*, a}$ Yuichi MAsuda, ${ }^{a}$ Naohito Abe, ${ }^{a}$ Masayoshi Oyama, ${ }^{a}$ Ryuichi SAwA, ${ }^{b}$ \\ Yoshikazu TAKAHASHI, ${ }^{b}$ Veliah CHELladURAI, ${ }^{c}$ and Munekazu IINUMA ${ }^{a}$ \\ ${ }^{a}$ Laboratory of Pharmacognosy, Gifu Pharmaceutical University; 1-25-4 Daigaku-nishi, Gifu 501-1196, Japan: ${ }^{b}$ Institute \\ of Microbial Chemistry, Tokyo; 3-14-23 Kamiosaki, Shinagawa-ku, Tokyo 141-0021, Japan: and ' Survey of Medicinal \\ Plant Unit, Central Council for Research in Ayurveda and Siddha; Tirunelveli-627002, Tamil Nadu, India. \\ Received June 23, 2010; accepted July 15, 2010; published online July 16, 2010
}

\begin{abstract}
Comprehensive re-investigation of the chemical constituents in the leaves of Vateria indica (Dipterocarpaceae) resulted in the isolation of a novel resveratrol dimeric dimer having a $\mathrm{C}_{2}$-symmetric structure, vateriaphenol F (1), and two new $O$-glucosides of resveratrol oligomers, vateriosides A (2) (resveratrol dimer) and B (4) (resveratrol tetramer), along with a new natural compound (3) and 33 known compounds including 26 resveratrol derivatives. The absolute structures were elucidated by spectroscopic analysis, including two dimensional NMR and circular dichroism (CD) spectra.
\end{abstract}

Key words Vateria indica; Dipterocarpaceae; leaf; resveratrol oligomer; absolute structure

Dipterocarpaceaeous plants have been known to have an abundance of stilbene oligomers that have a blocking unit of resveratrol. The woody plant Vateria indica LinN. (Dipterocarpaceae) is distributed in India and Sri Lanka, and the resin has been used as a traditional medicine for sore throat, chronic bronchitis, rheumatism, and diarrhea. ${ }^{1)}$ The stem of the genus Vateria is known to produce biologically active compounds such as oligostilbenoids and monoterpenes. ${ }^{2-6)}$ Our previous study demonstrated that the leaves also contain stilbene derivatives in high quantity. $\left.{ }^{6}\right)$ Recently, the bioactivities of stilbenoids isolated from Dipterocarpaceaeous plants have been reported to have antimicrobial activites, ${ }^{7,8)}$ antitumor activities, ${ }^{9-11)}$ and regulation of endoplasmic reticulum stress. ${ }^{12)}$ Though the leaves of $V$. indica are not used as medicines, the high content of stilbenes could be an important source of bioactive components. The stilbene oligomers characterized from this material are produced mainly by the homogeneous blocking unit resveratrol. The various structures are dependent upon the skeletal variation and the stereoisomers. Comprehensive investigation of the chemical constituents in the leaves of $V$. indica resulted in the isolation and characterization of a new resveratrol tetramer [vateriaphenol $\mathrm{F}$ (1)] and two new $O$-glucosides of resveratrol oligomers [vateriosides A (2) and B (4)], along with a new natural compound (3), and 33 known compounds [resveratrol derivatives (6-30), flavonols (31-33), diterpenes (34, 35), an isocoumarin (36), and a phenylpropanoid (37)]. The structures of the new compounds $(\mathbf{1}, \mathbf{2}, \mathbf{4})$ were elucidated by $2 \mathrm{D}$ NMR techniques such as ${ }^{1} \mathrm{H}-{ }^{1} \mathrm{H}$ correlation spectroscopy (COSY), ${ }^{13} \mathrm{C}-{ }^{1} \mathrm{H}$ COSY, and heteronuclear multiple bond connectivity (HMBC). Stereostructures were proposed by analysis of nuclear Overhauser effect spectroscopy (NOESY), differential rotating frame Overhauser enhancement (ROE), and ROESY spectra, as well as high-resolution (HR) FAB-MS and electrospray ionization (ESI)-MS analysis and circular dichroism (CD) spectroscopic properties. Vateriaphenol $\mathrm{F}(\mathbf{1})$ has a unique $\mathrm{C}_{2}$-symmetric structure.

\section{Results and Discussion}

Vateriaphenol F (1) and vaterioside A (2) were purified from an acetone extract of $V$. indica by open column chromatography on DMS, octadecyl silica (ODS), Silica gel, and
Sephadex LH-20, as well as HPLC. Vaterioside B (4) was purified from $\mathrm{MeOH}$ extract by repeated chromatography.

Vateriaphenol F (1) $\left([\alpha]_{D}^{25}-136^{\circ}\right)$, obtained as a pale-yellow solid, showed positive reaction to Gibbs reagent. The structure is composed of four resveratrol units $(\mathrm{A}-\mathrm{D}$; resveratrol $\mathrm{A}$ unit: i.e., between rings $\mathrm{A}_{1}$ and $\mathrm{A}_{2}$ via carbons $\mathrm{C}-7 \mathrm{a}$ and $\mathrm{C}-8 \mathrm{a}$ ). A detailed elucidation was carried out as follows. The molecular formula was assigned to $\mathrm{C}_{56} \mathrm{H}_{44} \mathrm{O}_{13}$ by HR-ESI-MS that showed a pseudomolecular ion $[\mathrm{M}+\mathrm{Na}]^{+}$at $\mathrm{m} / \mathrm{z}$ 947.2670, indicating 35 degrees of unsaturation. In the ${ }^{1} \mathrm{H}$ - and ${ }^{13} \mathrm{C}$-NMR spectra at $\mathrm{rt}$, some signals due to ring $\mathrm{A}_{2}$ were broadened in various solvents. In the ${ }^{1} \mathrm{H}$ NMR spectrum in acetone- $d_{6}$ at $-30^{\circ} \mathrm{C}$, the signals due to
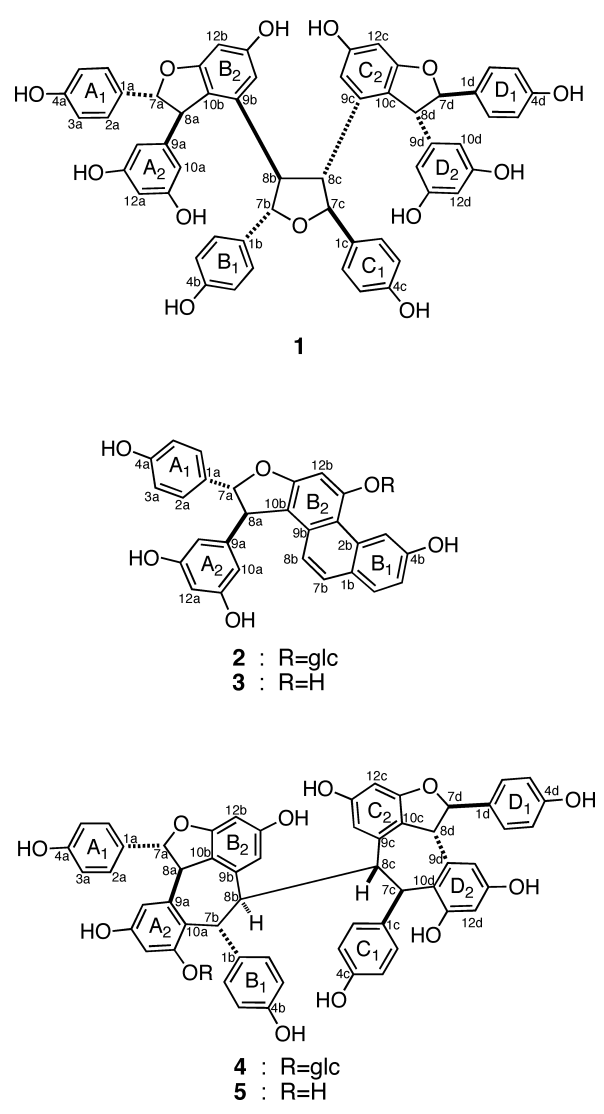

(C) 2010 Pharmaceutical Society of Japan 


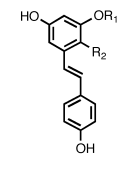

$6: \mathrm{R}_{1}=\mathrm{H}, \mathrm{R}_{2}=\mathrm{H}$ $7: \mathrm{R}_{1}=\mathrm{glc}, \mathrm{R}_{2}=\mathrm{H}$ $8: R_{1}=H, R_{2}=g l c$

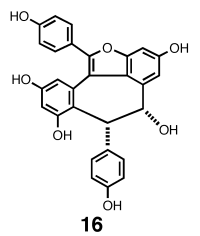

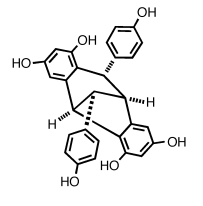

17

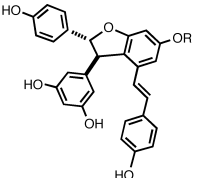

: $\mathrm{R}=\mathrm{H}$

11: $\mathrm{R}=\mathrm{H}=\mathrm{glc}$

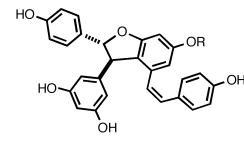

$12: \begin{aligned} & R=H \\ & 13: \\ & R=g l c\end{aligned}$

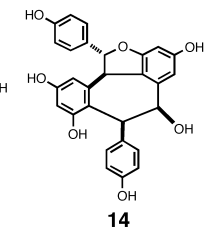

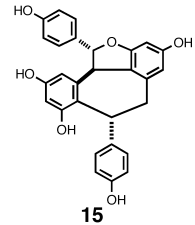

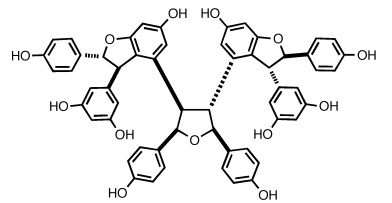

19
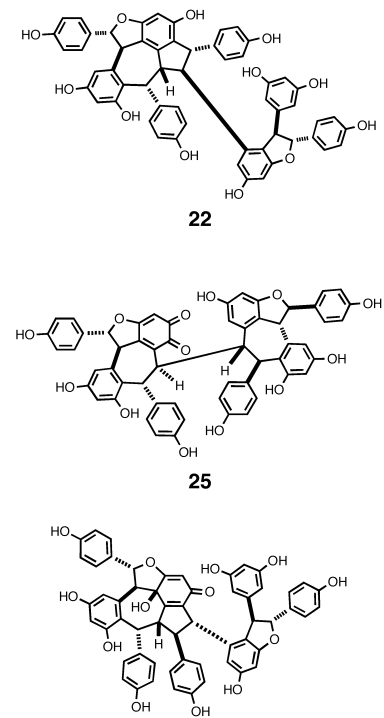

30

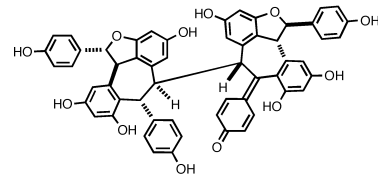

26

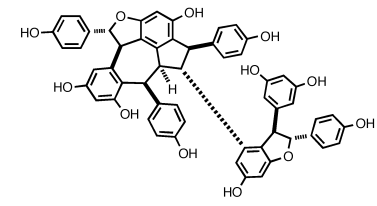

21
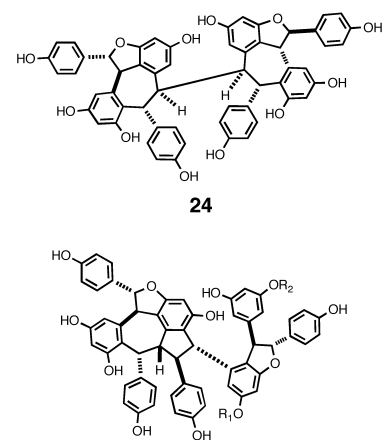

$27: \mathrm{R}_{1}=\mathrm{H}, \mathrm{R}_{2}=\mathrm{H}$ 28: $R_{1}=H, R_{2}=g l c$
29: $R_{1}=g l c, R_{2}=H$<smiles></smiles>

$31: \mathrm{R}_{1}=\mathrm{H}, \mathrm{R}_{2}=$ rha

$32: R_{1}=H, R_{2}=$ rha-rha 33: $\mathrm{R}_{1}=\mathrm{OH}, \mathrm{R}_{2}=$ rha

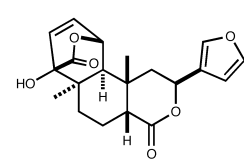

34

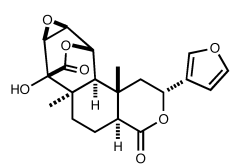

35

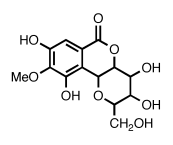

36

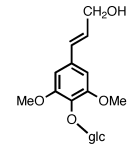

37 aromatic protons $(\mathrm{H}-10 \mathrm{a}$ and $\mathrm{H}-14 \mathrm{a})$ and carbons $(\mathrm{C}-10 \mathrm{a}, \mathrm{C}-$ 11a, C-13a, and C-14a) displayed sharpened signals. NMR data at $\mathrm{rt}$ and $-30^{\circ} \mathrm{C}$ were applied to the following structural analysis. Assignments of the ${ }^{1} \mathrm{H}$ - and ${ }^{13} \mathrm{C}-\mathrm{NMR}$ spectra of $\mathbf{1}$ in acetone- $d_{6}$ are shown in Table $1\left(-30^{\circ} \mathrm{C}\right)$. These assignments were developed primarily using ${ }^{1} \mathrm{H}-{ }^{1} \mathrm{H}$ COSY and ${ }^{1} \mathrm{H}-{ }^{13} \mathrm{C}$ heteronuclear single quantum coherence (HSQC) as well as HMBC experiments (Table 1). The ${ }^{13} \mathrm{C}$-NMR and distortionless enhancement by polarization transfer (DEPT)NMR spectra of 1 showed 24 signals for 28 carbons, including two oxygenated $s p^{3}$ carbons, two $s p^{3}$ methine carbons, nine $s p^{2}$ methine carbons, five $s p^{2}$ quaternary carbons, and six oxygenated $s p^{2}$ quaternary carbons. On the basis of the data stated above, compound 1 was considered to be a symmetrical dimeric dimer of resveratrol. Thirteen oxygen atoms and the odd degree of unsaturation indicated that two equivalent units form a heterocyclic ring. The NMR data showed the presence of two 4-hydroxylphenyl groups (rings $A_{1}$ and $\mathrm{B}_{1}$ ), a 3,5-dihydroxyphenyl group (ring $\mathrm{A}_{2}$ ), a 1,2,3,5-tetra- substituted benzene ring (ring $\mathrm{B}_{2}$ ), and two sets of aliphatic methane sequences $(\mathrm{C}-7 \mathrm{a} / \mathrm{C}-8 \mathrm{a}$ and $\mathrm{C}-7 \mathrm{~b} / \mathrm{C}-8 \mathrm{~b})$. In the HMBC spectrum (Fig. 1), significant ${ }^{3} J$ correlations were observed between $\mathrm{H}-7 \mathrm{a} / \mathrm{C}-2 \mathrm{a}(6 \mathrm{a}), \mathrm{H}-8 \mathrm{a} / \mathrm{C}-10 \mathrm{a}, \mathrm{H}-8 \mathrm{a} / \mathrm{C}-11 \mathrm{~b}, \mathrm{H}-$ $7 \mathrm{~b} / \mathrm{C}-2 \mathrm{~b}(6 \mathrm{~b})$, and $\mathrm{H}-8 \mathrm{~b} / \mathrm{C}-14 \mathrm{~b}$. These supported the connections between C-7a/C-1a, C-8a/C-9a, C-8a/C-10b, C-7b/C$1 \mathrm{~b}$, and C-8b/C-9b, respectively (Fig. 1A). The connection of the two units in $\mathbf{1}$ was unambiguously determined by HMBC as follows. The spectrum of $\mathbf{1}$ showed a triplet for the correlation between $\mathrm{H}-8 \mathrm{~b} / \mathrm{C}-8 \mathrm{c}$ and $\mathrm{H}-7 \mathrm{~b} / \mathrm{C}-7 \mathrm{c}$, which was interpreted by the overlap of a singlet from the long-range correlation and a doublet from the direct correlation (Fig. 2). Existence of a tetrahydrofuran ring $(\mathrm{C}-7 \mathrm{~b} / \mathrm{C}-8 \mathrm{~b} / \mathrm{C}-8 \mathrm{c} / \mathrm{C}-7 \mathrm{c} / \mathrm{O})$ was then confirmed by ${ }^{13} \mathrm{C}$ chemical shift of oxygenated methine carbons of C-7b and C-7c (Fig. 1B). Long-range correlations between $\mathrm{H}-7 \mathrm{a} / \mathrm{C}-11 \mathrm{~b}$ and $\mathrm{H}-7 \mathrm{~d} / \mathrm{C}-11 \mathrm{c}$ were not observed, but the presence of two dihydrobenzofuran rings (C-7a/C-8a/C-10b/C-11b/O and C-7d/C-8d/C-10c/C-11c/O) were deduced, considering the carbon chemical shifts and the 
Table 1. NMR Spectral Data of $\mathbf{1}$

\begin{tabular}{|c|c|c|c|}
\hline No. & $\delta_{\mathrm{H}}$ & $\delta_{\mathrm{C}}$ & HMBC \\
\hline 1a & & $131.7^{a)}$ & \\
\hline $2 a(6 a)$ & $6.96(\mathrm{~d}, 8.0)$ & $129.6^{b)}$ & $1 a, 2 a(6 a), 3 a(5 a), 4 a, 7 a$ \\
\hline $3 a(5 a)$ & $6.59(\mathrm{~d}, 8.0)$ & $115.4^{c, y)}$ & $1 \mathrm{a}, 3 \mathrm{a}(5 \mathrm{a})$ \\
\hline $4 a$ & & $157.9^{d)}$ & \\
\hline $7 \mathrm{a}$ & $5.09(\mathrm{~d}, 8.0)$ & $95.3^{e)}$ & $1 \mathrm{a}, 2 \mathrm{a}(6 \mathrm{a}), 8 \mathrm{a}, 9 \mathrm{a}, 10 \mathrm{~b}, 11 \mathrm{~b}$ \\
\hline $8 \mathrm{a}$ & $3.31(\mathrm{~d}, 8.0)$ & $55.5^{f)}$ & $7 a, 8 a, 10 a, 13 a, 14 a, 9 b, 11 b$ \\
\hline $9 \mathrm{a}$ & & $147.2^{g)}$ & \\
\hline $10 \mathrm{a}$ & $5.67(\mathrm{brs})$ & $105.9^{h)}$ & $8 \mathrm{a}, 11 \mathrm{a}$ \\
\hline $11 \mathrm{a}$ & & $159.9^{i)}$ & \\
\hline $12 \mathrm{a}$ & $6.25(t, 2.4)$ & $101.5^{j)}$ & $10 a, 11 a, 13 a, 14 a$ \\
\hline $13 \mathrm{a}$ & & $158.6^{k)}$ & \\
\hline $14 \mathrm{a}$ & $6.21(\mathrm{brs})$ & $108.7^{l)}$ & $8 \mathrm{a}, 10 \mathrm{a}, 12 \mathrm{a}$ \\
\hline $1 \mathrm{~b}$ & & $131.0^{m)}$ & \\
\hline $2 b(6 b)$ & $6.64(\mathrm{~d}, 8.0)$ & $129.1^{n)}$ & $2 b(6 b), 4 b, 7 b$ \\
\hline $3 b(5 b)$ & $6.54(\mathrm{~d}, 8.0)$ & $115.4^{o, y)}$ & $1 b, 3 b(5 b), 4 b$ \\
\hline $4 \mathrm{~b}$ & & $157.3^{p)}$ & \\
\hline $7 \mathrm{~b}$ & $5.17(\mathrm{~m})$ & $84.5^{q)}$ & $1 b, 2 b(6 b), 8 b, 9 b, 7 c$ \\
\hline $8 b$ & $3.58(\mathrm{~m})$ & $56.3^{r)}$ & $7 \mathrm{~b}, 8 \mathrm{c}, 9 \mathrm{~b}(9 \mathrm{c}), 10 \mathrm{~b}, 14 \mathrm{~b}$ \\
\hline $9 b$ & & $137.2^{s)}$ & \\
\hline $10 \mathrm{~b}$ & & $122.7^{t)}$ & \\
\hline $11 \mathrm{~b}$ & & $161.4^{u)}$ & \\
\hline $12 b$ & $6.09(\mathrm{~d}, 2.2)$ & $96.4^{v)}$ & $10 b, 11 b, 13 b, 14 b$ \\
\hline $13 b$ & & $158.8^{w)}$ & \\
\hline $14 \mathrm{~b}$ & $6.79(\mathrm{~d}, 2.2)$ & $106.2^{x)}$ & $8 b, 10 b, 12 b, 14 b$ \\
\hline $1 \mathrm{c}$ & & $131.0^{m)}$ & \\
\hline $2 c(6 c)$ & $6.64(\mathrm{~d}, 8.0)$ & $129.1^{n)}$ & $2 \mathrm{c}(6 \mathrm{c}), 4 \mathrm{c}, 7 \mathrm{c}$ \\
\hline $3 c(5 c)$ & $6.54(\mathrm{~d}, 8.0)$ & $115.4^{o)}$ & $1 c, 3 c(5 c), 4 c$ \\
\hline $4 c$ & & $157.3^{p)}$ & \\
\hline $7 \mathrm{c}$ & $5.17(\mathrm{~m})$ & $84.5^{q)}$ & $1 \mathrm{c}, 2 \mathrm{c}(6 \mathrm{c}), 8 \mathrm{c}, 9 \mathrm{c}, 7 \mathrm{~b}$ \\
\hline $8 \mathrm{c}$ & $3.58(\mathrm{~m})$ & $56.3^{r)}$ & $7 \mathrm{c}, 8 \mathrm{~b}, 9 \mathrm{c}(9 \mathrm{~b}), 10 \mathrm{c}, 14 \mathrm{c}$ \\
\hline $9 \mathrm{c}$ & & $137.2^{s)}$ & \\
\hline $10 \mathrm{c}$ & & $122.7^{t)}$ & \\
\hline $11 \mathrm{c}$ & & $161.4^{u)}$ & \\
\hline $12 \mathrm{c}$ & $6.09(\mathrm{~d}, 2.2)$ & $96.4^{v)}$ & $10 \mathrm{c}, 11 \mathrm{c}, 13 \mathrm{c}, 14 \mathrm{c}$ \\
\hline $13 \mathrm{c}$ & & $158.8^{w)}$ & \\
\hline $14 \mathrm{c}$ & $6.79(\mathrm{~d}, 2.2)$ & $106.2^{x)}$ & $8 \mathrm{c}, 10 \mathrm{c}, 12 \mathrm{c}, 14 \mathrm{c}$ \\
\hline $1 \mathrm{~d}$ & & $131.7^{a)}$ & \\
\hline $2 \mathrm{~d}(6 \mathrm{~d})$ & $6.96(\mathrm{~d}, 8.0)$ & $129.6^{b)}$ & $1 \mathrm{~d}, 2 \mathrm{~d}(6 \mathrm{~d}), 3 \mathrm{~d}(5 \mathrm{~d}), 4 \mathrm{~d}, 7 \mathrm{~d}$ \\
\hline $3 \mathrm{~d}(5 \mathrm{~d})$ & $6.69(\mathrm{~d}, 8.0)$ & $115.4^{c)}$ & $1 d, 3 d(5 d)$ \\
\hline $4 d$ & & $157.9^{d)}$ & \\
\hline $7 \mathrm{~d}$ & $5.09(\mathrm{~d}, 8.0)$ & $95.3^{e)}$ & $1 \mathrm{~d}, 2 \mathrm{~d}(6 \mathrm{~d}), 8 \mathrm{~d}, 9 \mathrm{~d}, 10 \mathrm{c}, 11 \mathrm{c}$ \\
\hline $8 \mathrm{~d}$ & $3.31(\mathrm{~d}, 8.0)$ & $55.5^{f}$ & $7 \mathrm{~d}, 8 \mathrm{~d}, 9 \mathrm{~d}, 10 \mathrm{~d}, 13 \mathrm{~d}, 14 \mathrm{~d}, 9 \mathrm{c}, 11 \mathrm{c}$ \\
\hline $9 \mathrm{~d}$ & & $147.2^{g)}$ & \\
\hline $10 \mathrm{~d}$ & $5.67(\mathrm{brs})$ & $105.9^{h)}$ & $8 \mathrm{~d}, 11 \mathrm{~d}$ \\
\hline $11 \mathrm{~d}$ & & $159.9^{i)}$ & \\
\hline $12 d$ & $6.25(\mathrm{t}, 2.4)$ & $101.5^{j)}$ & $10 \mathrm{~d}, 11 \mathrm{~d}, 13 \mathrm{~d}, 14 \mathrm{~d}$ \\
\hline $13 \mathrm{~d}$ & & $158.6^{k)}$ & \\
\hline $14 d$ & $6.21(\mathrm{brs})$ & $108.7^{l)}$ & $8 \mathrm{~d}, 10 \mathrm{~d}, 12 \mathrm{~d}$ \\
\hline
\end{tabular}

Measured in acetate- $d_{6}$ at $600 \mathrm{MHz}\left({ }^{1} \mathrm{H}-\mathrm{NMR}\right)$ and $\left.150 \mathrm{MHz}\left({ }^{13} \mathrm{C}-\mathrm{NMR}\right) . a-x\right)$ Overlapping. $y$ ) Interchangeable.

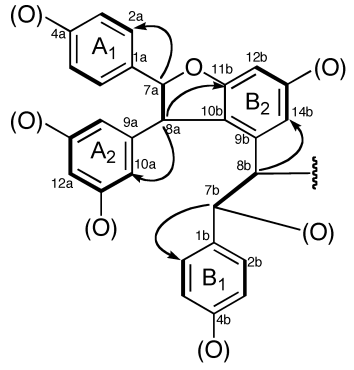

A

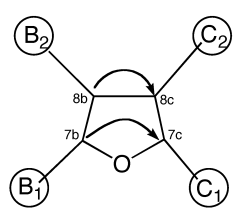

B

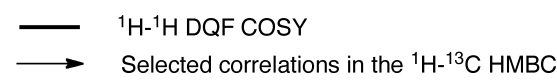

Fig. 1. Selected Correlations in $2 \mathrm{D}$ NMR $\left(-30^{\circ} \mathrm{C}\right)$ in the Partial Structures $(\mathrm{A}, \mathrm{B})$ of $\mathbf{1}$

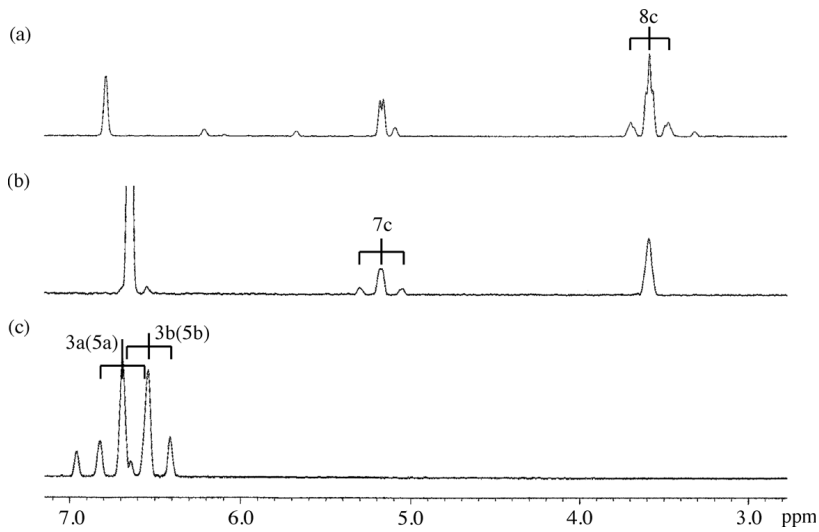

Fig. 2. HMBC Spectrum $\left(-30^{\circ} \mathrm{C}\right)$ of $\mathbf{1} . F_{1}$ Traces at the Positions of (a) C-7c $\left(\delta_{\mathrm{C}} 56.3\right)$, (b) C-8b $\left(\delta_{\mathrm{C}} 84.5\right)$, and (c) C-3a(5a) and C-3b $(5 \mathrm{~b})\left(\delta_{\mathrm{C}}\right.$ 115.38; Center of Close Signals, 115.37 and 115.39)

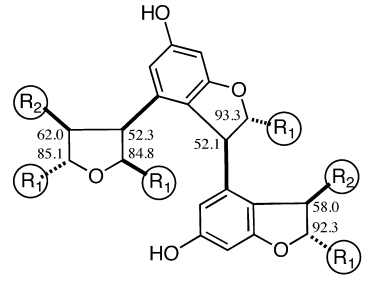

kobophenol A

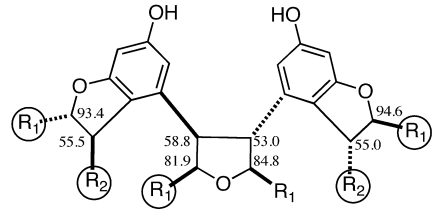

grandiphenol A (19) $\mathrm{R}_{1}:$ 4-hydroxylphenyl
$\mathrm{R}_{2}: 3,5$-dihydroxyphenyl

Fig. 3. Structures and Spectroscopic Data $\left(\delta_{\mathrm{C}}\right.$ in Acetone- $\left.d_{6}\right)$ of Kobophenol A and Grandiphenol A (19)

molecular formula. The carbon chemical shifts $\left[\delta_{\mathrm{C}} 84.5(\mathrm{C}-\right.$ $7 \mathrm{~b}, \mathrm{C}-7 \mathrm{c})$ and $\left.\delta_{\mathrm{C}} 56.3(\mathrm{C}-8 \mathrm{~b}, \mathrm{C}-8 \mathrm{c})\right]$ are typical for C-atoms of a tetrahydrobenzofuran moiety, and those of the carbons [ $\delta_{\mathrm{C}} 95.3(\mathrm{C}-7 \mathrm{a}, \mathrm{C}-7 \mathrm{~d})$ and $\left.\delta_{\mathrm{C}} 55.5(\mathrm{C}-8 \mathrm{a}, \mathrm{C}-8 \mathrm{~d})\right]$ are also similar to those of the dihydrobenzofuran moieties, such as those of kobophenol $\mathrm{A}^{13)}$ and grandiphenol A (19) ${ }^{14)}$ (Fig. 3). The existence of two dihydrobenzofuran rings and a tetrahydrofuran ring was confirmed by comparison of these data. The planar structure of vateriaphenol $\mathrm{F}$ was then concluded to be $\mathbf{1}$. The other correlations in the HMBC spectrum, as summarized in Table 1, were in accordance with the proposed planar structure.

The stereostructure was determined from the results of ROESY and the differential ROE experiments supported by the consideration of interrupted rotations of $\mathrm{C}-\mathrm{C}$ bonds, anisotropy, and the energy-minimized structure of $\mathbf{1}$ in Merck-modified force field (MMFF). The trans orientations of $\mathrm{H}-7 \mathrm{a} / \mathrm{H}-8 \mathrm{a}$ and $\mathrm{H}-7 \mathrm{~b} / \mathrm{H}-8 \mathrm{~b}$ on the furan rings were confirmed by the distinctive ROE correlations between $\mathrm{H}-7 \mathrm{a} / \mathrm{H}-$ 10a, H-8a/H-2a(6a), H-7b/H-14b, and H-8b/H-2b(6b) (Fig. 4). The molecule has $\mathrm{C}_{2}$-symmetry and it is not a meso form. Hence, four carbons on the dihydrobenzofuran rings have the same relative configurations [C-7a, C-8a, C-7d, and C-8d $($ rel- $R$ )]. The two methine protons of $\mathrm{H}-8 \mathrm{~b}$ and $\mathrm{H}-8 \mathrm{c}$ must be antisituated, which proposed two possible relative structures shown as $\mathbf{1}$ or $\mathbf{1}^{\prime}$ in Fig. 4. To gain the accurate conformation of these two candidates, the minimum energy conformation was obtained using the PCMODEL suite of programs with 

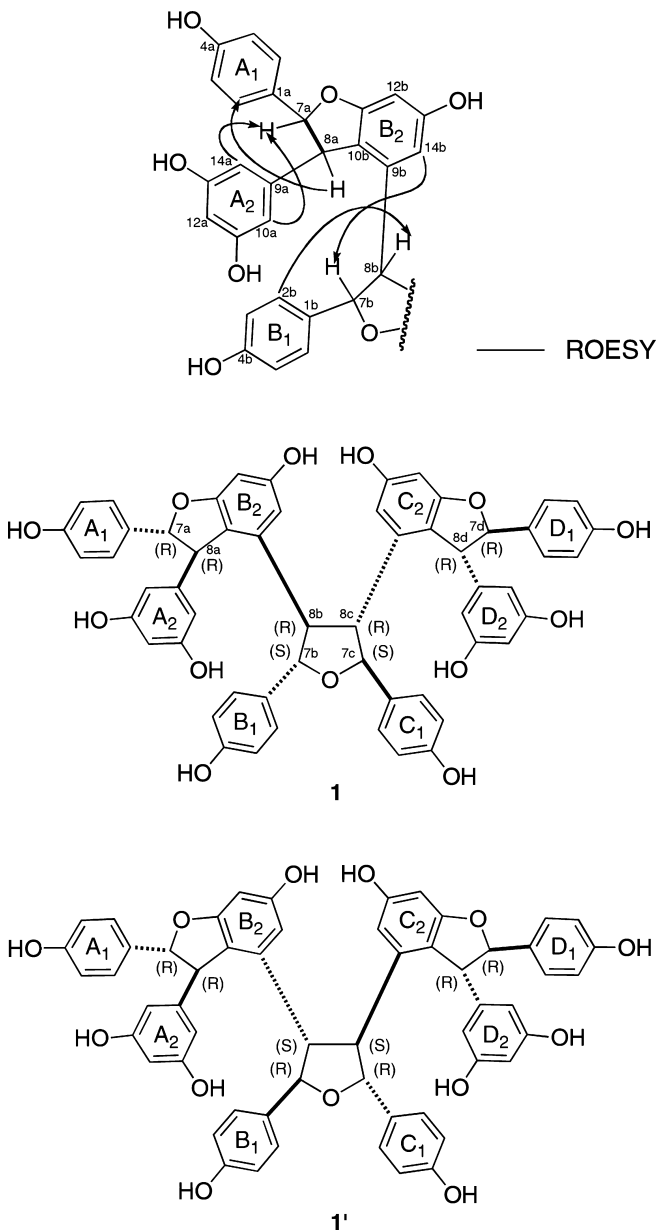

Fig. 4. Selected ROEs Observed in $\mathbf{1}$ and Two Possibilities of Relative Stereostructures (1 and $\left.\mathbf{1}^{\prime}\right)$

MMFF [Figs. 5a for $\mathbf{1}, \mathrm{b}$ for $\left.\mathbf{1}^{\prime}\right]^{15)}$ The key point for the differentiation of the two was an intense ROE cross-peak $(\mathrm{H}-$ 14b/H-8d). As shown in Fig. 5, the protons [H-14b/H-8d (c)] are neighbors in $\mathbf{1}$, while they are never in such a situation in $\mathbf{1}^{\prime}$. Based on these results, the relative configuration of eight asymmetric carbons (C-7a, C-8a, C-7b, C-8b, C-7c, C-8c, C$7 \mathrm{~d}$, and $\mathrm{C}-8 \mathrm{~d}$ ) in $\mathbf{1}$ were determined to be rel- $R, R, S, R, S, R$, $R$, and $R$, respectively. There are pairs of equivalent protons that are indistinguishable by the conventional NMR methods, making differentiation of the ROESY correlation impossible. For example, the important ROE between H-14b/H-8d [Fig. $5 \mathrm{c}$ ] from $\mathrm{H}-14 \mathrm{~b} / \mathrm{H}-8 \mathrm{a}\left(c^{\prime}\right)$ could not be differentiated because the protons $(\mathrm{H}-8 \mathrm{~d}$ and $\mathrm{H}-8 \mathrm{a})$ are equal. The differentiation of appropriate ROE correlations and inappropriate ROE correlations is essential. The practical ROESY correlations are depicted as $a-c$. In the differential ROE experiment, irradiation of H-14b enhanced three methine signals in the order $\mathrm{H}$ $7 \mathrm{~b}(a), \mathrm{H}-8 \mathrm{c}(b)$, and $\mathrm{H}-8 \mathrm{~d}(c)$ [Fig. 5c]. The inappropriate ROE, H-14b/H-7c $\left(a^{\prime}\right)$, is excluded because $\mathrm{H}-7 \mathrm{c}$ and the ring $\mathrm{B}_{2}$ are situated in the opposite side of reference plane. $\mathrm{ROE}\left[\mathrm{H}-14 \mathrm{~b} / \mathrm{H}-8 \mathrm{a}\left(c^{\prime}\right)\right]$ is unreasonable due to the skeleton. When the intensity of ROE $(a)$ is considered, the hindered rotation of $\mathrm{C}-\mathrm{C}$ bonds $(\mathrm{C}-8 \mathrm{~b} / \mathrm{C}-9 \mathrm{~b})$ is supported, and the $\mathrm{C}-\mathrm{C}$ bond $(\mathrm{C}-9 \mathrm{~b} / \mathrm{C}-14 \mathrm{~b})$ and $\mathrm{H}-7 \mathrm{~b}$ must be located on the same side of reference plane, which can explain the weak intensity of ROE $(b)$ and impossibility of the inappropriate one $\left(b^{\prime}\right)$.
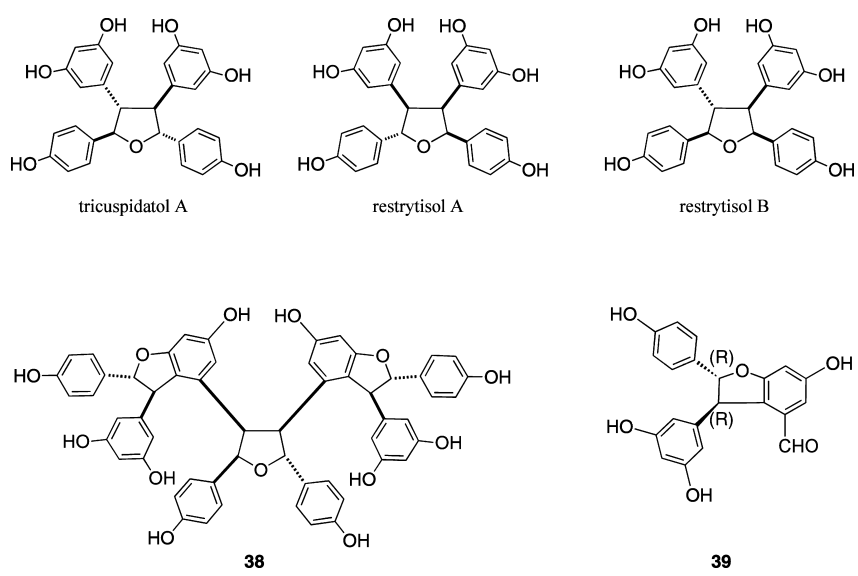

Supporting evidence for the strong ROE $(a)$ and the inappropriate one $\left(b^{\prime}\right)$ is obtained from the energy-minimized stereostructure of 1 (Fig. 5). This shows a dihedral angle of $170.2^{\circ}$ for the bonds, $\mathrm{H}-8 \mathrm{~b} / \mathrm{C}-8 \mathrm{~b}$ and $\mathrm{C}-9 \mathrm{~b} / \mathrm{C}-14 \mathrm{~b}$, and an all-equatorial situation of four rings $\left(B_{1}, B_{2}, C_{1}\right.$, and $\left.C_{2}\right)$ attached to the tetrahydrofuran ring. The rationalized relations between $\mathrm{H}$ $7 \mathrm{~b} / \mathrm{H}-8 \mathrm{~b} / \mathrm{H}-8 \mathrm{c} / \mathrm{H}-7 \mathrm{c}$ are antiperiplanar; the allocated orientations were in accordance with the calculated dihedral angles $168.5^{\circ}$ for $\mathrm{H}-7 \mathrm{~b} / \mathrm{C}-7 \mathrm{~b}-\mathrm{H}-8 \mathrm{~b} / \mathrm{C}-8 \mathrm{~b}$ and $173.9^{\circ}$ for $\mathrm{H}-8 \mathrm{~b} / \mathrm{C}-$ $8 \mathrm{~b}-\mathrm{H}-8 \mathrm{c} / \mathrm{C}-8 \mathrm{c}$. The calculated distances between the protons that displayed ROE with $\mathrm{H}-14 \mathrm{~b}$ were correlated with those of ROE intensities, i.e., H-14b/H-7b ( $a$ : $2.222 \AA), \mathrm{H}-14 \mathrm{~b} / \mathrm{H}-8 \mathrm{c}$ (b: $2.600 \AA)$, and $\mathrm{H}-14 \mathrm{~b} / \mathrm{H}-8 \mathrm{~d}$ (c: $3.100 \AA)$. The model can reasonably explain the anisotropic effect of the rings $A_{2}$ and $\mathrm{B}_{1}$, which causes upper field shift of aromatic protons, $\mathrm{H}$ $2 \mathrm{~b}(6 \mathrm{~b})\left(\delta_{\mathrm{H}} 6.64\right)$ and H-14a $\left(\delta_{\mathrm{H}} 5.67\right)$, respectively. The energy-minimized structure of $\mathbf{1}^{\prime}$ can never be suitable for each consideration based on ROEs and anisotropy [Fig. 5b].

Vateriaphenol F (1) has the same partial structure as (-)$\varepsilon$-viniferin (10), ${ }^{16}$ the main constituent of this substance. From the viewpoint of biogenetic pathways, $\mathbf{1 0}$ could be a precursor of 1 and the configuration of corresponding carbons of 1 (C-7a, C-8a, C-7d, and C-8d) are all absolute $R$ configurations. If this conjecture is adopted, the absolute structure of $\mathbf{1}$ is determined. However, the configuration of carbons on two 3-(3,5-dihydroxyphenyl)-2,3-dihydro-6-hydroxy-2-(4-hydroxyphenyl)-4-benzofuranyl groups of grandiphenol B $(\mathbf{3 8})^{14,17)}$ is opposite, which requires clarification with spectroscopic evidence. The absolute configuration of 1 was assigned based on the CD spectroscopic evidence [Fig. 6a]. The CD spectroscopic evidence related to a transoriented dihydrobenzofuran ring is as follows. Lemiere et al. reported that the configurations at $\mathrm{C}-7$ and $\mathrm{C}-8$ of the dihydrobenzofuran skeleton can be distinguished in the range of $220-240 \mathrm{~nm}$ by CD spectroscopy. ${ }^{18)}$ We reported the CD evidence of $(-)-\varepsilon$-viniferin and its oxidative derivative [(2R,3R)-3-(3,5-dihydroxyphenyl)-6-hydroxy-2-(4-hydroxyphenyl)-2,3-dihydrobenzofuran-4-carbaldehyde: 39] [negative Cotton effect at $236-237 \mathrm{~nm}] .{ }^{19)}$ The structure of 1 also has an all-equatorial substituted tetrahydrobenzofuran ring. Unfortunately, CD spectroscopic evidence has not been reported for tricuspidatol $\mathrm{A},{ }^{20)}$ restrytisols $\mathrm{A}$ and $\mathrm{B}^{21)}$ On the other hand, a similar structure is shown by 2,5-diaryltetrahydrofuran lignan derivatives, which are prominently present in CD spectroscopic data. In the case of 2,5-diaryltetrahydrofurans bearing anti-oriented aromatic rings, the absolute con- 
(a)

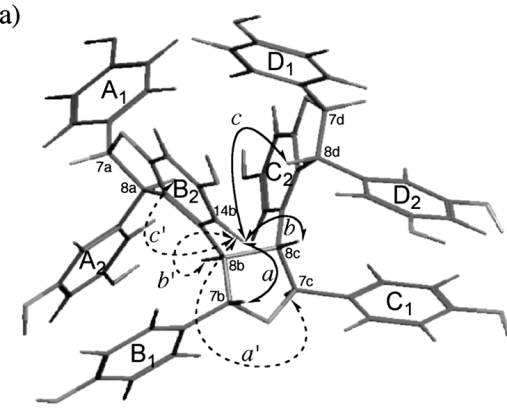

1

_a-c: appropriate ROEs for 1

$a^{\prime}-c^{\prime}$ : inappropriate ROEs for 1

\begin{tabular}{cc} 
& distances $(\AA)$ \\
\hline$a$ & 2.222 \\
$b$ & 2.600 \\
$c$ & 3.100
\end{tabular}

(b)

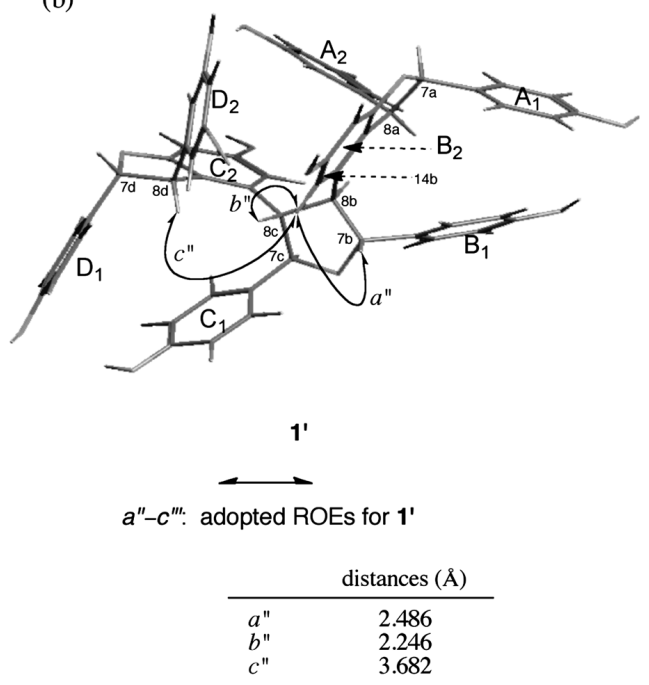

(c)
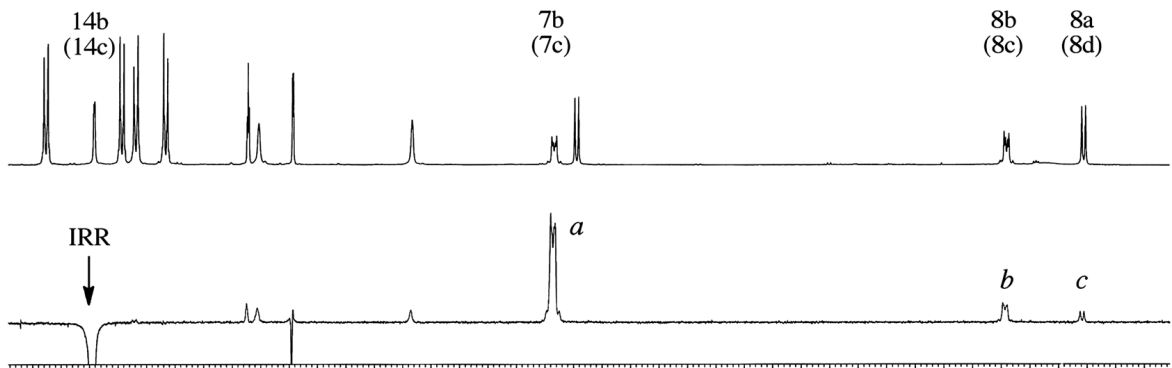

Fig. 5. (a, b) Energy-Minimized Stereostructures of $\mathbf{1}$ and $\mathbf{1}^{\prime}$, Appropriate ROEs Based on Calculated Distances $(a-c)$ and Inappropriate ROEs $\left(a^{\prime}-c^{\prime}\right)$ for 1, and Adopted ROEs for Inappropriate Structure $\left(\mathbf{1}^{\prime}\right)\left(a^{\prime \prime}-c^{\prime \prime}\right)$ (MMFF94 Calculation Using the PCMODEL 9.1 Molecular Modeling Program), (c) Differential ROE Spectrum $\left(-30^{\circ} \mathrm{C}\right)$ of $\mathbf{1}$

figuration of two oxymethine carbons can be established by comparison of the $\mathrm{CD}$ curve. Prasad et al. reported that the configurations at C-2 and C-5 of the 2,5-diaryltetrahydrofuran skeleton can be distinguished by the region 230 250 nm. ${ }^{17)}$ Namely, $S$-absolute configurations of C-2 and C-5 in the molecules will display a strong negative Cotton effect. The CD spectra of $\mathbf{1}$ displayed an extensive negative Cotton signal at $238 \mathrm{~nm}[\Delta \varepsilon-113.8(c=10.1 \mu \mathrm{M}, \mathrm{MeOH})]$; the sign and wavelength maxima are consistent with those of 39 [negative, $236 \mathrm{~nm}$ Fig. 6b] and $(2 S, 5 S)$-diveratryl-( $3 R, 4 S)$-dimethyltetrahydrofuran (negative, 239, $243 \mathrm{~nm}$ ), which suggests that 1 bears absolute configurations of $7 \mathrm{a}-R, 8 \mathrm{a}-R$, $7 \mathrm{~b}-S, 8 \mathrm{~b}-R, 7 \mathrm{c}-S, 8 \mathrm{c}-R, 7 \mathrm{~d}-R$, and $8 \mathrm{~d}-R$. However, two 3-(3,5dihydroxyphenyl)-2,3-dihydro-6-hydroxy-2-(4-hydroxyphenyl)-4-benzofuranyl groups in the diaryltetrahydrofuran ring of 1 would bring about additional effects on the Cotton curve, requiring exact understanding of which substituents are further associated with the curve in the region 220 $250 \mathrm{~nm}$. Grandiphenols A (19) and B (38) are stereoisomers of $1,{ }^{14)}$ the relative configurations of which were determined in our previous study; 7a- $R, 8 \mathrm{a}-R, 7 \mathrm{~b}-R, 8 \mathrm{~b}-R, 7 \mathrm{c}-S, 8 \mathrm{c}-R$, $7 \mathrm{~d}-R$, and $8 \mathrm{~d}-R$ for 19 and $7 \mathrm{a}-R, 8 \mathrm{a}-R, 7 \mathrm{~b}-R, 8 \mathrm{~b}-R, 7 \mathrm{c}-R, 8 \mathrm{c}-$ $S, 7 \mathrm{~d}-S$, and $8 \mathrm{~d}-S$ for 38 . When the CD curves of $\mathbf{1}$ and 19 are compared, a difference is observed in intensity of the negative Cotton effects at $238 \mathrm{~nm}$ [19: $\Delta \varepsilon-50.0(c=10.1$ $\mu \mathrm{M}, \mathrm{MeOH})]$, which indicated that the configurational differ- ence of $\mathrm{C}-7 \mathrm{~b}$ contributes to the results because $\mathbf{1 9}$ is an epimer of $\mathbf{1}$ of C-7b. Supporting evidence is obtained by comparison of the conformation of the tetrahydrofuran rings of 1 and 19. The $\mathrm{C}-\mathrm{C}$ bonds, $\mathrm{C}-1 \mathrm{~b} / \mathrm{C}-7 \mathrm{~b}$ and $\mathrm{C}-1 \mathrm{c} / \mathrm{C}-7 \mathrm{c}$, are situated anti orientation in $\mathbf{1}$ and indicate left-handed rotation, which would contribute largely to the negative Cotton effects at $238 \mathrm{~nm}$, while that of $\mathbf{1 9}$ is syn oriented and contribute quite less to the Cotton curve. The intensity of the negative Cotton effects at $238 \mathrm{~nm}$ of $\mathbf{1 9}$ is almost twice that of 39 [CD $(c=27.5 \mu \mathrm{M}, \mathrm{MeOH}) \mathrm{nm}(\Delta \varepsilon)$ : $236(-23.3)]$, suggesting the following important points: (1) the absolute configurations of $\mathbf{1}$ and $\mathbf{1 9}$ are presented as $7 \mathrm{a}-R, 8 \mathrm{a}-R, 7 \mathrm{~b}-S, 8 \mathrm{~b}-$ $R, 7 \mathrm{c}-S, 8 \mathrm{c}-R, 7 \mathrm{~d}-R$, and $8 \mathrm{~d}-R$ and $7 \mathrm{a}-R, 8 \mathrm{a}-R, 7 \mathrm{~b}-R, 8 \mathrm{~b}-R$, $7 \mathrm{c}-S, 8 \mathrm{c}-R, 7 \mathrm{~d}-R$, and $8 \mathrm{~d}-R$, respectively, and (2) the two synoriented aromatic rings $\mathrm{B}_{1}$ and $\mathrm{C}_{1}$ of 19 contribute quite less to the Cotton effects at $238 \mathrm{~nm}$. The CD spectroscopic properties of $\mathbf{3 8}$ are discussed as follows. A negative Cotton effect at $238 \mathrm{~nm}$ by the two 3-(3,5-dihydroxyphenyl)-2,3-dihydro-6-hydroxy-2-(4-hydroxyphenyl)-4-benzofuranyl groups are supposed to offset each other because they are enantiomeric substituents in 38. The two trans-oriented aromatic rings $\mathrm{B}_{1}$ and $\mathrm{C}_{1}$ of $\mathbf{3 8}$ would have a large influence on the negative Cotton effects at $238 \mathrm{~nm}$ [38: $\Delta \varepsilon-34.4(c=10.1$ $\mu \mathrm{M}, \mathrm{MeOH})]$. Further database study on the CD spectra and a comparative discussion on stereoisomers $\mathbf{1}$, as well as an $\mathrm{X}$ ray crystallographic approach, are required for elucidating 
the absolute structure of $\mathbf{1}$.

The results obtained from ${ }^{1} \mathrm{H}-\mathrm{NMR}$ spectra at various temperatures (Fig. 7) implied that ring $\mathrm{A}_{2}$ of $\mathbf{1}$ does not rotate freely because of the steric hindrance due to neighboring substituent(s) and/or other factors. There are four $\mathrm{C}-\mathrm{C}$ bonds bearing rotational restriction in $\mathbf{1}(\mathrm{C}-8 \mathrm{a} / \mathrm{C}-9 \mathrm{a}, \mathrm{C}-8 \mathrm{~b} / \mathrm{C}-9 \mathrm{~b}, \mathrm{C}-$ $8 \mathrm{c} / \mathrm{C}-9 \mathrm{c}$, and C-8d/C-9d), which is the first case explained for stilbenoids. The restricted free rotation of the $\mathrm{C}-\mathrm{C}$ bond of

(a)

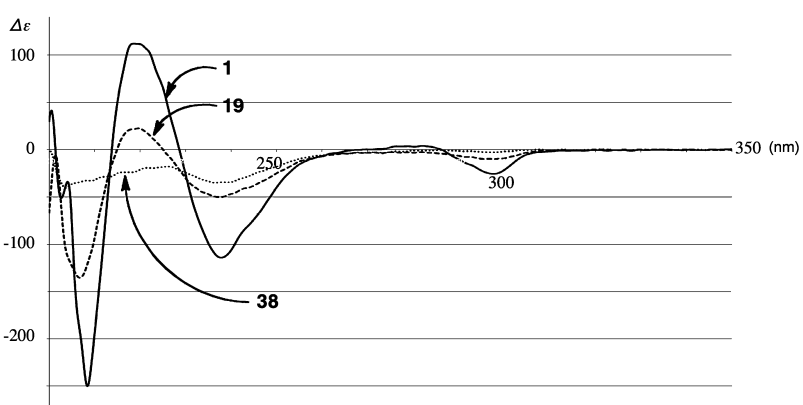

(b)

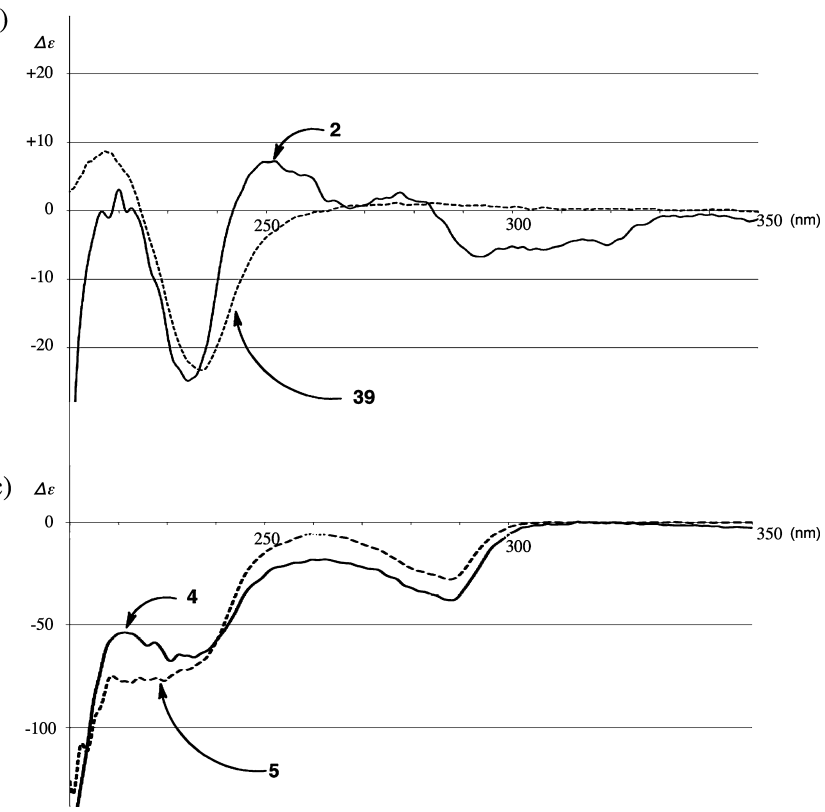

Fig. 6. CD Spectra of (a) Vateriaphenol F (1), Grandiphenols A (19) and B (38), (b) Vaterioside A (2), (2R,3R)-3-(3,5-Dihydroxyphenyl)-6-hydroxy2-(4-hydroxyphenyl)-2,3-dihydrobenzofuran-4-carbaldehyde (39), (c) Vaterioside B (4), and (-)-hopeaphenol (5)

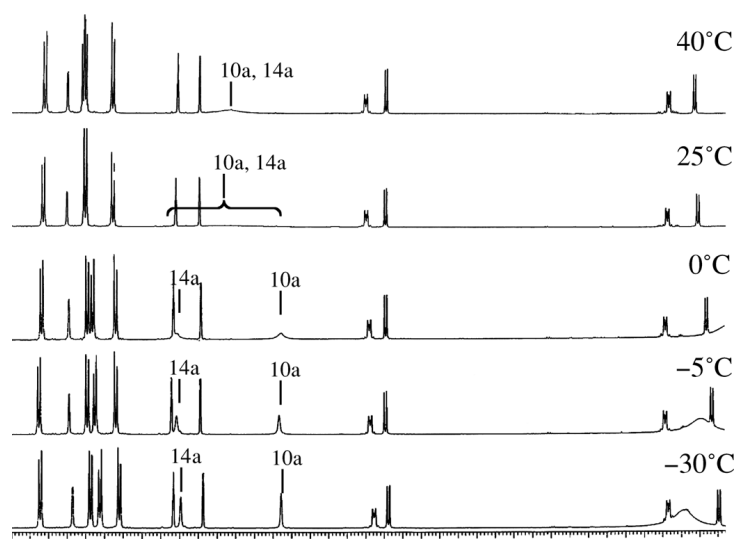

Fig. 7. ${ }^{1} \mathrm{H}-\mathrm{NMR}$ Spectra (Acetone- $d_{6}, 600 \mathrm{MHz}$ ) of $\mathbf{1}$ at Variable Temperatures
C- $8 \mathrm{~b} / \mathrm{C}-9 \mathrm{~b}$ and $\pi-\pi$ interaction between rings $\mathrm{A}_{2} / \mathrm{B}_{1}$ would be the important factors reflected in the spectroscopic behavior of ring $\mathrm{A}_{2}$. Similar phenomena were also observed in a 4hydroxyl group in vaticanol $\mathrm{G}^{22}$ and a 3,5-dihydroxyl group in grandiphenol A (19). ${ }^{14)}$ As discussed in previous articles, the behavior of some protons in stilbene oligomers is very complicated. . $^{3,22-25)}$ Therefore, further spectroscopic evidence in connection with steric factors are required for the accurate determination of the configuration in stilbene oligomers such as $\mathbf{1}$ and related compounds.

The planar structure of $\mathbf{1}$ is identical to those of known resveratrol tetramers $\mathbf{1 9}, \mathbf{3 8},{ }^{14)}$ and viniferol $\mathrm{E}^{26)}$ In the case of $\mathbf{1}$, two identical dimeric units are fused to produce a tetrahydrofuran ring. Half signals of the total atom numbers are observed in their ${ }^{1} \mathrm{H}$ - and ${ }^{13} \mathrm{C}$-NMR spectra. In the cases of 19, 38, and viniferol $\mathrm{E}$, two hetero-stereogenic dimeric units form each molecule. There has been an increased number of naturally occurring $\mathrm{C}_{2}$-symmetric stilbenoids represented by (-)-hopeaphenol. ${ }^{27)}$ Kawabata et al. developed the heteronuclear multiple quantum coherence (HMQC)-ROESY sequence for detection of ROEs between equivalent protons which cannot be observed by conventional NMR methods. ${ }^{28)}$ During the structure elucidation of $\mathbf{1}$, we analyzed the ${ }^{13} \mathrm{C}$ coupled heteronuclear single quantum coherence (HSQC)ROESY spectrum. At first, we measured the spectrum of (-)-hopeaphenol (5) and compared the result with those of Kawabata et al.; we reproduced the result. The result obtained for 1 (data not shown) included poor information in that only one ROE-relayed negative cross-peak appeared between $\mathrm{H}-8 \mathrm{~b} / \mathrm{C}-8 \mathrm{~b}$; this can reasonably explain the symmetry of 1 and restricted rotation of the $C-C$ bonds $C-8 b / C-9 b$ and C-8c/C-9c.

Two signals $[\mathrm{H}-7 \mathrm{~b}(\mathrm{H}-7 \mathrm{c})$ and $\mathrm{H}-8 \mathrm{~b}(\mathrm{H}-8 \mathrm{c})]$ in the ${ }^{1} \mathrm{H}-\mathrm{NMR}$ spectrum of 1 display six-peak multiplicity, which was resolved by $J$-spectroscopy and homodecoupled experiments (Fig. 8). The methine protons (H-8b and $\mathrm{H}-8 \mathrm{c})$ display six peaks [Fig. 8a, $a-f$ ] due to ${ }^{1} \mathrm{H}-\mathrm{NMR}$ spectroscopic features in the $J$-spectrum. If two weak peaks $(a, f)$ are ignored, the peaks $b-e$ appear to be a double doublet signal $(J=7.1$, $3.0 \mathrm{~Hz}$ ) [Fig. 8a, A], which is consistent with the coupling pattern of tricuspidatol A $(J=6.0,2.0 \mathrm{~Hz}$; measured at $200 \mathrm{MHz})^{21)}$ Decoupling of $\mathrm{H}-7 \mathrm{~b}(\mathrm{H}-7 \mathrm{c})$ causes disappearance of four main peaks $(b-e)$ and appearance of a sharp signal $(h)$, which proves that $\mathrm{H}-8 \mathrm{~b}(\mathrm{H}-8 \mathrm{c})$ bears an $A X X^{\prime}$ system rather than an $A X$ system $\left({ }^{3} J_{A X}=7.1 \mathrm{~Hz},{ }^{5} J_{A X^{\prime}}=3.0 \mathrm{~Hz}\right)$ [Fig. 8b]. The small coupling constant $\left({ }^{5} J_{A X^{\prime}}\right)$ is explained by a $W$ coupling in the tetrahydrofuran ring. Decoupling of $\mathrm{H}-$ $8 \mathrm{~b}(\mathrm{H}-8 \mathrm{c})$ also simplified the spin system $(g)$. J-Spectroscopy indicated that the two weak peaks $(a, f)$ are components of the signal. The multiplicity of H-7c and H-8c was not completely removed when $\mathbf{1}$ was irradiated by a second radiofrequency $(g, h)$, which suggested existence of another coupling system. The signals $(g, h)$ display two spin systems of type $A B$ with a small difference in chemical shift $\left[\left(\delta_{A}-\delta_{B}\right)=0\right]$ compared with the coupling constant $\left(J_{A B}=8.8 \mathrm{~Hz}\right)$ [Fig. 8c]. This coupling corresponds to B for $\mathrm{H}-8 \mathrm{~b}(\mathrm{H}-8 \mathrm{c})$ that displays $8.8 \mathrm{~Hz}$ (peaks $a$ and $b$ ) in Fig. 8a. These couplings observed in $g$ and $h$ may be explained by coupling between $\mathrm{H}-7 \mathrm{~b} / \mathrm{H}-7 \mathrm{c}$ and $\mathrm{H}-8 \mathrm{~b} / \mathrm{H}-8 \mathrm{c}$, but the exact reason is not clear.

Vaterioside $\mathrm{A}(2)\left([\alpha]_{\mathrm{D}}^{25}-50^{\circ}\right)$, obtained as a pale-yellow solid, showed positive reaction to Gibbs reagent. The molec- 
(a)

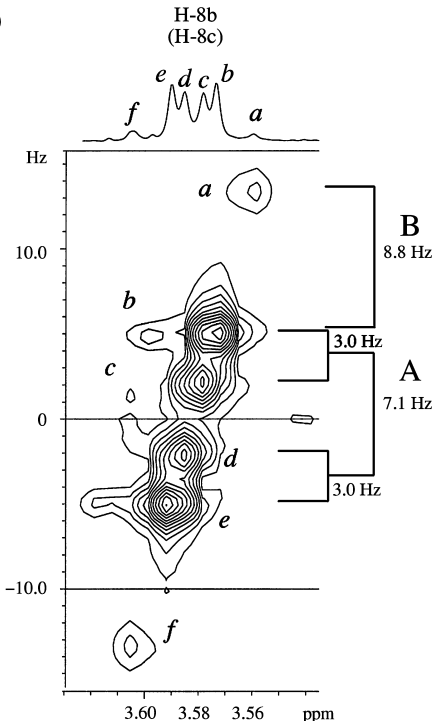

(b)
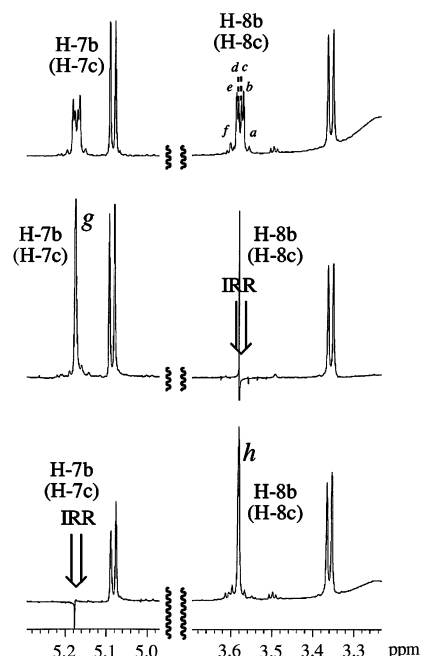

(c)
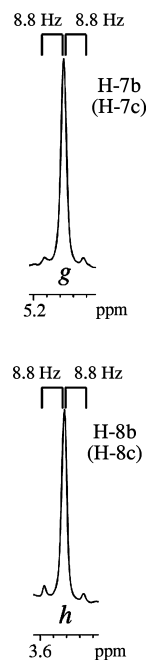

Fig. 8. ${ }^{1} \mathrm{H}-\mathrm{NMR}$ Experiments $\left(-5^{\circ} \mathrm{C}\right)$ of $\mathbf{1}$

(a) Magnification of homonuclear $J$-spectrum. Cross-peaks observed for H-8b (H-8c). (b, c) Parts of homodecoupled spectra by irradiation of $\mathrm{H}-8 \mathrm{~b}(\mathrm{H}-8 \mathrm{c})$ and $\mathrm{H}-7 \mathrm{~b}(\mathrm{H}-7 \mathrm{c})$.

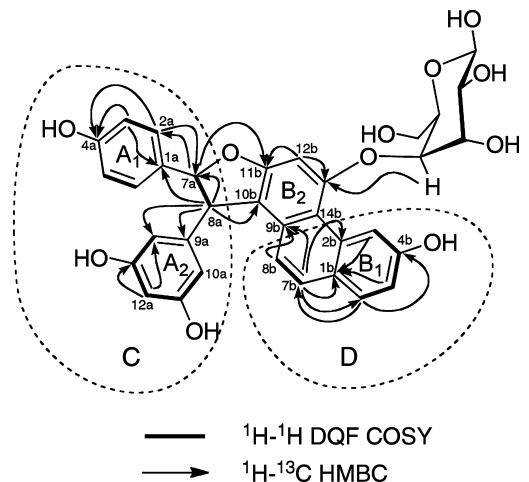

Fig. 9. Partial Structures (C, D) and Correlations in 2D NMR in of $\mathbf{2}$

ular formula of $\mathrm{C}_{34} \mathrm{H}_{30} \mathrm{O}_{11}$ was established by an $[\mathrm{M}+\mathrm{H}]^{+}$ ion peak at $\mathrm{m} / \mathrm{z} 615.1850$ in HR-FAB-MS together with NMR spectroscopic data. ${ }^{1} \mathrm{H}$ - and ${ }^{13} \mathrm{C}-\mathrm{NMR}$ spectroscopic data together with ${ }^{1} \mathrm{H}-{ }^{1} \mathrm{H}$ COSY, ${ }^{13} \mathrm{C}-{ }^{1} \mathrm{H}$ COSY and HMBC spectra (Fig. 9, Table 2) showed the presence of ortho-coupled aromatic protons assignable to a 4-hydroxylphenyl group (ring $A_{1}$ ), a 3,5-dihydroxyphenyl group $\left(A_{2}\right)$, and a 1,2,4-trisubstituted benzene ring (ring $\mathrm{B}_{1}$ ). NMR spectroscopic data also disclosed the presence of a set of aliphatic signals characteristic for a 2,3-diaryldihydrobenzofuran moiety $(\mathrm{H}-7 \mathrm{a} / \mathrm{H}-8 \mathrm{a}),{ }^{11)}$ cis-coupled olefinic protons $(\mathrm{H}-7 \mathrm{~b} / \mathrm{H}-8 \mathrm{~b})$, an $O$ - $\beta$-glucopyranosyl moiety $\left[\delta_{\mathrm{H}} 5.39(1 \mathrm{H}, \mathrm{d}, J=8.0 \mathrm{~Hz}\right.$, glc-H-1) and $\delta_{\mathrm{C}} 102.6,74.2,71.1,77.8,78.4$ and 62.4], and four phenolic hydroxyl groups $\left(\delta_{\mathrm{H}} 8.16-8.59\right)$. In the HMBC spectrum (Fig. 1), significant ${ }^{3} J$ correlations were observed between $\mathrm{H}-7 \mathrm{a} / \mathrm{C}-2 \mathrm{a}(6 \mathrm{a}), \mathrm{H}-8 \mathrm{a} / \mathrm{C}-10 \mathrm{a}(14 \mathrm{a})$, and $\mathrm{H}-$ $7 \mathrm{~b} / \mathrm{C}-6 \mathrm{~b}$, which supports the connections between $\mathrm{C}-1 \mathrm{a} / \mathrm{C}-7 \mathrm{a}$, C-8a/C-9a, and C-1b/C-7b, respectively (Figs. 9C, D). The remaining ring system of $\mathbf{2}$ and connectivities were determined as follows. The presence of a six-membered ring system (ring $\mathrm{B}_{2}$ ) was substantiated by ${ }^{13} \mathrm{C}-\mathrm{NMR}$ signals (Table 2), with five quaternary $s p^{2}$ carbons (C-9b, C-10b, C-11b, C$13 \mathrm{~b}$, and $\mathrm{C}-14 \mathrm{~b}$ ), and a hydrogenated $s p_{2}$ carbon $(\mathrm{C}-12 \mathrm{~b})$. The important correlations of HMBC measurements for the
Table 2. ${ }^{1} \mathrm{H}$ - and ${ }^{13} \mathrm{C}-\mathrm{NMR}$ Spectral Data of $\mathbf{2}$ and $\mathbf{3}$

\begin{tabular}{|c|c|c|c|c|}
\hline \multirow{2}{*}{ No. } & \multicolumn{2}{|l|}{$2^{a)}$} & \multicolumn{2}{|l|}{3} \\
\hline & $\delta_{\mathrm{H}}$ & $\delta_{\mathrm{C}}$ & $\delta_{\mathrm{H}}{ }^{b)}$ & $\delta_{\mathrm{C}}{ }^{c}$ \\
\hline 1a & & 133.7 & & 133.6 \\
\hline $2 a(6 a)$ & $7.26(\mathrm{~d}, 8.8)$ & 128.1 & $6.88(\mathrm{~d}, 8.8)$ & 127.7 \\
\hline $3 a(5 a)$ & $6.84(\mathrm{~d}, 8.8)$ & 116.2 & $6.48(\mathrm{~d}, 8.8)$ & 115.8 \\
\hline $4 \mathrm{a}$ & & 158.3 & & 159.3 \\
\hline $7 \mathrm{a}$ & $5.53(\mathrm{~d}, 5.4)$ & 94.5 & $5.53(\mathrm{~d}, 5.4)$ & 94.2 \\
\hline $8 \mathrm{a}$ & $4.76(\mathrm{~d}, 5.4)$ & 57.7 & $4.76(\mathrm{~d}, 5.4)$ & 57.4 \\
\hline $9 \mathrm{a}$ & & 147.1 & & 147.8 \\
\hline $10 \mathrm{a}, 14 \mathrm{a}$ & $6.16(\mathrm{~d}, 2.0)$ & 106.8 & $6.16(\mathrm{~d}, 2.0)$ & 106.5 \\
\hline $11 a, 13 a$ & $8.16(\mathrm{~s})$ & 159.8 & $8.16(\mathrm{~s})$ & 159.5 \\
\hline $12 \mathrm{a}$ & 6.23 (brs) & 102.2 & 6.23 (brs) & 101.8 \\
\hline $1 b$ & & 126.2 & & $125.6^{d)}$ \\
\hline $2 b$ & & 133.3 & & 133.7 \\
\hline $3 b$ & $9.21(\mathrm{~d}, 2.4)$ & 113.2 & $9.21(\mathrm{~d}, 2.4)$ & 112.8 \\
\hline $4 \mathrm{~b}$ & & 157.0 & & 159.1 \\
\hline $5 b$ & $7.06(\mathrm{dd}, 8.8,2.4)$ & 116.1 & $7.06(\mathrm{dd}, 8.8,2.4)$ & 115.2 \\
\hline $6 \mathrm{~b}$ & $7.68(\mathrm{~d}, 8.8)$ & 130.6 & $7.68(\mathrm{~d}, 8.8)$ & 130.0 \\
\hline $7 \mathrm{~b}$ & $7.51(\mathrm{~d}, 8.8)$ & 129.4 & $7.51(\mathrm{~d}, 8.8)$ & 128.9 \\
\hline $8 \mathrm{~b}$ & $7.11(\mathrm{~d}, 8.8)$ & 120.4 & $7.11(\mathrm{~d}, 8.8)$ & 120.4 \\
\hline $9 b$ & & 132.3 & & $132.3^{d)}$ \\
\hline $10 \mathrm{~b}$ & & 116.8 & & 114.4 \\
\hline $11 \mathrm{~b}$ & & 159.6 & & $158.0^{e)}$ \\
\hline $12 \mathrm{~b}$ & $7.16(\mathrm{~s})$ & 96.9 & $7.16(\mathrm{~s})$ & 97.1 \\
\hline $13 b$ & & 159.7 & & $156.9^{e)}$ \\
\hline $14 \mathrm{~b}$ & & 116.0 & & 114.6 \\
\hline Glucose-1 & $5.39(\mathrm{~d}, 8.0)$ & 102.6 & & \\
\hline Glucose-2 & $3.97(\mathrm{~m})$ & 74.2 & & \\
\hline Glucose-3 & $3.59(\mathrm{~m})$ & 71.1 & & \\
\hline Glucose-4 & $3.69(\mathrm{~m})$ & 77.8 & & \\
\hline Glucose-5 & $3.65(\mathrm{~m})$ & 78.4 & & \\
\hline Glucose-6 & $3.95,3.75(\mathrm{~m})$ & 62.4 & & \\
\hline $\mathrm{OH}(11 \mathrm{a}, 13 \mathrm{a})$ & $8.16(\mathrm{brs})$ & & 8.16 (brs) & \\
\hline $\mathrm{OH}(13 b)$ & & & $8.42(\mathrm{brs})$ & \\
\hline $\mathrm{OH}$ & 8.42 (brs) & & 8.42 (brs) & \\
\hline & 8.59 (brs) & & 8.59 (brs) & \\
\hline
\end{tabular}

a) Measured in acetone- $d$ at $400 \mathrm{MHz}\left({ }^{1} \mathrm{H}-\mathrm{NMR}\right)$ and $\left.100 \mathrm{MHz}\left({ }^{13} \mathrm{C}-\mathrm{NMR}\right), \quad b\right)$ Measured in acetone- $d_{6}$ at $400 \mathrm{MHz}$. c) Measured in acetone- $d_{6} 75 \mathrm{MHz}\left({ }^{13} \mathrm{C}\right.$ NMR). $\left.{ }^{29)} \quad d, e\right)$ Revised assignments. 
fused cyclic system of the ring $\mathrm{B}_{2}$ were as follows: $\mathrm{H}-7 \mathrm{a} / \mathrm{C}-$ $11 \mathrm{~b}\left({ }^{3} J\right)$ and $\mathrm{H}-8 \mathrm{a} / \mathrm{C}-10 \mathrm{~b}\left({ }^{2} J\right)$ for the formation of a diaryldihydrobenzofuran moiety (Fig. 9C). The carbons, C-9b-C$14 \mathrm{~b}$, observed at $\delta_{\mathrm{C}} 132.3,116.8,159.6,96.9,159.7$, and 116.0, are assigned to a 3,5-dioxygenated benzene ring. Similar patterns in the same partial structure were also observed in $3\left(\delta_{\mathrm{C}} 132.3,114.4,158.0,97.1,156.9\right.$, and 114.6), $\left.{ }^{29}\right)$ where the carbon atom $(\mathrm{C}-13 \mathrm{~b})$ was substituted by a hydroxyl group instead of glucosyloxy group (Table 2). The location of the glucosyloxy group is $\mathrm{C}-13 \mathrm{~b}$ as confirmed by the HMBC cross-peak between the anomeric proton $\left(\delta_{\mathrm{H}} 5.39\right)$ and the aromatic carbon at $\delta_{\mathrm{C}} 159.7(\mathrm{C}-13 \mathrm{~b})$. The remaining $O$-function was assigned to $\mathrm{OH}$ groups. Based on these results, the planar structure of $\mathbf{2}$ was confirmed. The stereostructure was determined from the results of the differential NOE experiments and CD spectrum. The trans orientations of $\mathrm{H}-7 \mathrm{a} / \mathrm{H}-8 \mathrm{a}$ on the dihydrobenzofuran rings were confirmed by the distinctive NOEs between $\mathrm{H}-7 \mathrm{a} / \mathrm{H}-10 \mathrm{a}(14 \mathrm{a})$ and $\mathrm{H}-8 \mathrm{a} / \mathrm{H}-2 \mathrm{a}, 6 \mathrm{a}$. Compound 2 exhibited the Cotton signal at $235 \mathrm{~nm}[\Delta \varepsilon-24.7(c=27.5 \mu \mathrm{M}, \mathrm{MeOH})]$, the sign and wavelength maxima are consistent with those of 39, suggesting that the two carbons $(\mathrm{C}-7 \mathrm{a}$ and $\mathrm{C}-8 \mathrm{a})$ of the proposed relative structure 2 have the same absolute configuration as 39 [Fig. 6b]. The glucose stereogenicity of $\mathbf{2}$ does not interfere with the exciton coupling that defines the furan stereogenic centers through exciton coupling observed at $235-236 \mathrm{~nm}$. Consequently, the structure of vaterioside A (2) was concluded to be $(2 R, 3 R)$ - 2,3-dihydro-2-(4-dihydroxyphenyl)-3(3,5-dihydroxyphenyl)-10-( $\beta$-glucopyransoyloxy)-phenanthro[2,1- $b]$ furan- 8 -ol. The isolation of $\mathbf{3}$ from natural sources is novel, while a photo-oxidative product from $\varepsilon$-viniferin (10) has been reported. ${ }^{29)}$

Vaterioside B (4) was obtained as a pale-yellow amorphous solid. The composition was deduced to be $\mathrm{C}_{62} \mathrm{H}_{52} \mathrm{O}_{17}$ from the pseudo-molecular ion peak of $[\mathrm{M}+\mathrm{Na}]^{+}$at $\mathrm{m} / \mathrm{z}$ 1091.3065 in the ESI-MS spectrum and the ${ }^{13} \mathrm{C}-\mathrm{NMR}$ spectrum which showed 62 carbon signals. The ${ }^{1} \mathrm{H}$ - and ${ }^{13} \mathrm{C}$ NMR spectroscopic data (Table 3) of $\mathbf{4}$ showed signals for a $\beta$-glucopyranosyl moiety $\left[\delta_{\mathrm{H}} 4.87(1 \mathrm{H}, \mathrm{d}, J=7.6 \mathrm{~Hz}\right.$, glc-H$1)$ and $\delta_{\mathrm{C}} 101.9,74.5,77.6,71.7,77.6$, and 63.2]. Acid hydrolysis of 4 with $\mathrm{HCl}$ in $\mathrm{H}_{2} \mathrm{O}$ gave 5 . These results indicated that 4 was a $\beta$-glucopyranoside of hopeaphenol. To confirm the location of the glucosidic linkage, the ${ }^{1} \mathrm{H}$ - and ${ }^{13} \mathrm{C}$-NMR signals were assigned by double quantum filtered (DQF) COSY, HMQC, and HMBC spectroscopic data (Table 3). In the NOESY experiment, the aromatic proton $\left(\delta_{\mathrm{H}} 6.85\right)$ assignable to $\mathrm{H}-12 \mathrm{a}$ displays a distinct cross-peak with the anomeric proton. Therefore, the glucosyl moiety should be attached to $\mathrm{C}-11 \mathrm{a}$ of $\mathbf{5}$. The absolute configuration and the strong negative optical rotation of the (-)-hopeaphenol $\left([\alpha]_{\mathrm{D}}^{28}-402.9^{\circ}\right)$ have been reported. The negative optical rotation of the aglycone can be assumed by the specific rotation of $4\left([\alpha]_{\mathrm{D}}^{25}-189^{\circ}\right)$ even if the influence of the glucosyloxy group is considered. The CD spectra of $\mathbf{4}$ displayed the same features as those of $\mathbf{5}$ [Fig. 6c]. These data suggest that $\mathbf{5}$ has the same absolute configuration as 4 . Therefore vaterioside $\mathrm{B}$ (4) was elucidated to be (-)-hopeaphenol $11 \mathrm{a}-O$ - $\beta$-glucopyranoside.

In addition to the resveratrol oligomers described above (1-5, 10, and 19), 23 known resveratrol derivatives were isolated and their structures identified as resveratrol (6), pi-
Table 3. NMR Spectral Data of 4

\begin{tabular}{|c|c|c|c|}
\hline No. & $\delta_{\mathrm{H}}$ & $\delta_{\mathrm{C}}$ & HMBC \\
\hline $1 \mathrm{a}$ & & 130.9 & \\
\hline $2 a(6 a)$ & $7.11(\mathrm{~d}, 8.8)$ & 130.2 & $2 \mathrm{a}(6 \mathrm{a}), 4 \mathrm{a}, 7 \mathrm{a}$ \\
\hline $3 a(5 a)$ & $6.78(\mathrm{~d}, 8.8)$ & 116.0 & $3 a(5 a), 4 a$ \\
\hline $4 a$ & & 158.5 & \\
\hline $7 \mathrm{a}$ & $5.72(\mathrm{~d}, 12.6)$ & 88.1 & $1 \mathrm{a}, 8 \mathrm{a}, 9 \mathrm{a}$ \\
\hline $8 \mathrm{a}$ & $4.17(\mathrm{~d}, 12.6)$ & 49.7 & $1 \mathrm{a}, 7 \mathrm{a}, 9 \mathrm{a}, 10 \mathrm{~b}$ \\
\hline $9 \mathrm{a}$ & & 142.4 & \\
\hline $10 \mathrm{a}$ & & 123.3 & \\
\hline $11 \mathrm{a}$ & & 159.3 & \\
\hline $12 \mathrm{a}$ & $6.85(\mathrm{~d}, 2.0)$ & 102.1 & $10 \mathrm{a}, 11 \mathrm{a}, 13 \mathrm{a}$ \\
\hline $13 \mathrm{a}$ & & 157.2 & \\
\hline $14 \mathrm{a}$ & 6.41 (brs) & 108.4 & $8 \mathrm{a}, 10 \mathrm{a}, 13 \mathrm{a}$ \\
\hline $1 \mathrm{~b}$ & & 134.3 & \\
\hline $2 b(6 b)$ & $6.95(\mathrm{~d}, 8.8)$ & 129.3 & $2 b(6 b), 4 b, 7 b$ \\
\hline $3 b(5 b)$ & $6.59(\mathrm{~d}, 8.8)$ & 115.2 & $1 b, 3 b(5 b), 4 b$ \\
\hline $4 \mathrm{~b}$ & & 155.6 & \\
\hline $7 b$ & $5.86(\mathrm{brs})$ & 41.3 & $9 \mathrm{a}, 8 \mathrm{c}$ \\
\hline $8 b$ & 3.87 (brs) & 48.5 & \\
\hline $9 b$ & & 140.4 & \\
\hline $10 \mathrm{~b}$ & & 118.6 & \\
\hline $11 b$ & & 158.5 & \\
\hline $12 b$ & $5.75(\mathrm{~d}, 2.0)$ & 95.3 & $10 \mathrm{~b}, 14 \mathrm{~b}$ \\
\hline $13 b$ & & 157.4 & \\
\hline $14 b$ & $5.14(\mathrm{~d}, 2.0)$ & 111.4 & $8 b, 10 b, 12 b, 13 b$ \\
\hline $1 \mathrm{c}$ & & 135.1 & \\
\hline $2 c(6 c)$ & $6.80(\mathrm{~d}, 8.8)$ & 129.5 & $4 c, 7 c$ \\
\hline $3 c(5 c)$ & $6.53(\mathrm{~d}, 8.8)$ & 115.2 & $1 c, 3 c(5 c), 4 c$ \\
\hline $4 \mathrm{c}$ & & 155.6 & \\
\hline $7 \mathrm{c}$ & 5.93 (brs) & 41.3 & $8 \mathrm{~b}, 9 \mathrm{~d}, 11 \mathrm{~d}$ \\
\hline $8 \mathrm{c}$ & 3.87 (brs) & 48.3 & \\
\hline $9 \mathrm{c}$ & & 140.3 & \\
\hline $10 \mathrm{c}$ & & 118.6 & \\
\hline $11 \mathrm{c}$ & & 159.4 & \\
\hline $12 \mathrm{c}$ & $5.75(\mathrm{~d}, 2.0)$ & 95.3 & $10 \mathrm{c}, 14 \mathrm{c}$ \\
\hline $13 c$ & & 157.2 & \\
\hline $14 \mathrm{c}$ & $5.21(\mathrm{~d}, 2.0)$ & 111.4 & $8 c, 10 c, 12 c, 13 c$ \\
\hline $1 \mathrm{~d}$ & & 131.0 & \\
\hline $2 d(6 d)$ & $7.17(\mathrm{~d}, 8.4)$ & 130.2 & $2 \mathrm{~d}(6 \mathrm{~d}), 4 \mathrm{~d}, 7 \mathrm{~d}$ \\
\hline $3 d(5 d)$ & $6.82(\mathrm{~d}, 8.4)$ & 129.3 & $2 \mathrm{~d}, 3 \mathrm{~d}(5 \mathrm{~d}), 4 \mathrm{~d}$ \\
\hline $4 d$ & & 158.5 & \\
\hline $7 d$ & $5.78(\mathrm{~d}, 12.4)$ & 88.3 & $1 \mathrm{~d}, 8 \mathrm{~d}, 9 \mathrm{~d}$ \\
\hline $8 \mathrm{~d}$ & $4.34(\mathrm{~d}, 12.4)$ & 49.9 & $1 \mathrm{~d}, 7 \mathrm{~d}, 10 \mathrm{c}$ \\
\hline $9 d$ & & 142.4 & \\
\hline $10 \mathrm{~d}$ & & 121.0 & \\
\hline $11 d$ & & 159.0 & \\
\hline $12 d$ & $6.55(\mathrm{~d}, 2.0)$ & 101.3 & $10 \mathrm{~d}, 13 \mathrm{~d}, 14 \mathrm{~d}$ \\
\hline $13 d$ & & 157.2 & \\
\hline $14 \mathrm{~d}$ & $6.33(\mathrm{brs})$ & 106.6 & $8 \mathrm{~d}, 10 \mathrm{~d}, 12 \mathrm{~d}, 13 \mathrm{~d}$ \\
\hline Glucose-1 & $4.87(\mathrm{~d}, 7.6)$ & 101.9 & \\
\hline Glucose-2 & $3.17(\mathrm{~m})$ & 74.5 & $8 \mathrm{~d}, 11 \mathrm{~d}$ \\
\hline Glucose-3 & $3.37(\mathrm{~m})$ & 77.6 & \\
\hline Glucose-4 & $2.96(\mathrm{~m})$ & 71.7 & $10 \mathrm{~d}, 11 \mathrm{~d}, 13 \mathrm{~d}, 14 \mathrm{~d}$ \\
\hline Glucose-5 & $3.42(\mathrm{~m})$ & 77.6 & \\
\hline Glucose-6 & $3.58,3.83(\mathrm{~m})$ & 63.2 & $8 \mathrm{~d}, 10 \mathrm{~d}, 12 \mathrm{~d}$ \\
\hline
\end{tabular}

Measured in acetate- $d_{6}$ at $400 \mathrm{MHz}\left({ }^{1} \mathrm{H}-\mathrm{NMR}\right)$ and $100 \mathrm{MHz}\left({ }^{13} \mathrm{C}-\mathrm{NMR}\right)$.

ceid (7), 4- $\beta$-glucopyranosyl-5-[(1E)-2-(4-hydroxyphenyl)ethenyl]-bezene-1,3-diol (8), ${ }^{30)}$ 2- $\beta$-glucopyranosyloxyphenanthrene-4,6-diol (9), ${ }^{31)}$ paucifloroside A (11), ${ }^{23)}$ cis- $(-)-\varepsilon$ viniferin $(\mathbf{1 2}){ }^{32)}$ upunoside D (13), ${ }^{33)}$ balanocarpol (14), ${ }^{34)}$ melanoxylin A (15), ${ }^{35)}$ malibatol (16), ${ }^{36)}$ (-)-ampelopsin F (17), ${ }^{37)}$ pauciflorol B (18), ${ }^{23)}$ vaticanol C (20), ${ }^{38)}$ hemsleyanols C (21) and D (22), ${ }^{39)}$ pauciflorol C (23), ${ }^{23)}$ vateriaphenol B (24), ${ }^{4)}$ nepalensinol G (25), ${ }^{40)}$ stenophyllol A (26), ${ }^{41)}$ vaticanol B (27), ${ }^{38)}$ vaticasides B (28) and C (29), ${ }^{42)}$ and upunaphenol $\mathrm{F}$ (30). ${ }^{43}$ ) The other known compounds 
were identified to be flavonols [kaempferol 3-O-rhamnoside (31) ${ }^{44)}$ kaempferol 3-O-rhamnopyranosyl-( $\left.\rightarrow 2\right)$-rhamnopyranoside (32), and quercitrin $(\mathbf{3 3})^{45)}$ ], diterpenes [columbin $(34)^{46)}$ and palmarin $(35)^{47)}$, bergenin (36), ${ }^{11)}$ and syringin (37). ${ }^{28,48)}$ Resveratrol derivatives in the leaves of $V$. indica display planar structural diversity due to the following: (1) degree of oligomerization ranging to tetramer (monomers: 6-9; dimers: 2, 3, 10-17; trimer: 18; tetramers: $\mathbf{1}-\mathbf{3}$ and 19-30), (2) variation in the skeleton comprising dihydrobenzofuran(s) $(\mathbf{1}-\mathbf{5}, \mathbf{1 0}-\mathbf{1 5}$, and 18-30), tetrahydrofuran (1 and 19), phenanthrene (2, 3, and 10), cycloheptadiene (14-16 and 23-26), bicyclo[3.2.1] octadiene (17 and 20), bicyclo[5.3.0]decadiene $(\mathbf{1 8}, \mathbf{2 1}, \mathbf{2 2}$, and 27-30), 2,3-dihydrobenzofuran-5,6-dione (25), 4-methylenecyclohexa-2,5dienone (26), 3,3a-dihydrobenzofuran-6(2H)-one (30), and (3) $C$ - or $O$-glucosylation $(2,4,7-9,11,13,28$, and 29). This is the first time that occurrence of the groups flavonolrhamnoside $(\mathbf{3 2})$ and diterpenoids $(34,35)$ has been reported in the family Dipterocarpaceae. Compounds $(\mathbf{6}, \mathbf{8}, \mathbf{9}, \mathbf{1 1}-\mathbf{1 3}$, 15-19, 21-23, and 30) have been isolated for the first time from $V$. indica. Interestingly, the leaves of $V$. indica are supposed to have two biosynthetic pathways, according to the coexistence of stilbene synthase and chalcone synthase that gives stilbene, e.g., resveratrol (6) (blocking unit of $\mathbf{1}-\mathbf{5}$ and 7-30) or chalcones, e.g., naringenin-chalcone (precursor of 31-33), respectively. Isolation of flavonoids from the stem bark has not been reported. The small quantity of $\mathbf{6}$ suggested that the material accumulates resveratrol derivatives mainly by oligomerization and glycosylation in Dipterocarpaceae. The multifunctional bioactivity of $\mathbf{6}$ for treatment and prevention of diseases has been documented. ${ }^{49)}$ Recently, its oligomers were also proven to have versatile functionalities, as demonstrated by $\mathbf{2 0}{ }^{9,10)}$ and $27 .{ }^{12)}$ The disease-preventive effects of flavonoids and the anti-gastric-ulcer effect of $\mathbf{3 6},{ }^{50)}$ in addition to the stomach-protective effect of $34,{ }^{51}$ would make the leaves of $V$. indica an important material. The present study and our knowledge of polyphenols suggest that the leaves of the family Dipterocarpaceae are a substantial source of useful polyphenols and terpenoids that could be applied to medicinal uses and/or the prevention of diseases.

\section{Experimental}

The instruments used in the present study are detailed as follows: optical rotations, JASCO P-1020 polarimeter; CD spectra, JASCO J-820 spectrometer (in $\mathrm{MeOH}$ solution); UV spectra, Shimadzu UV-3100 spectrophotometer (in $\mathrm{MeOH}$ solution); ${ }^{1} \mathrm{H}$ - and ${ }^{13} \mathrm{C}$-NMR spectra, JEOL JNM ECA-600 and AL-400 (chemical shift values are presented as $\delta$ values with tetramethylsilane (TMS) as the internal standard); ESI-MS, Thermo Fisher Scientific LTQ Orbitrap instrument; and FABMS, JEOL JMS-DX-300 instrument.

The following adsorbents were used for purification: analytical TLC, Merck Kieselgel $60 \mathrm{~F}_{254}(0.25 \mathrm{~mm})$; preparative TLC, Merck Kieselgel 60 $\mathrm{F}_{254}(0.5 \mathrm{~mm})$; open column chromatography, Merck Kieselgel 60, Pharmacia Fine Chemicals AB Sephadex LH-20, and Fuji Silysia Chemical Chromatorex DMS; and vacuum liquid chromatography (VLC), Merck Kieselgel 60. A Waters Sep-Pak Vac 35cc (10 g) C18 cartridge was used for smallscale reversed-phase (RP) open column chromatography. The following system was used for preparative HPLC: LC-6AD pump, a SIL-10AXL auto injector, a SCL-10AVP system controller, and a SPD-10AV UV-Vis absorbance detector, equipped by CLASS-VP software. The separation was performed on a Capcell Pak $\mathrm{C}_{18}$ UG120 S-5 column $(5 \mu \mathrm{m}, 250 \times 10.0 \mathrm{~mm}$ SHISEIDO, Japan) at $40^{\circ} \mathrm{C}$. The flow-rate of the mobile phase was $5 \mathrm{ml} / \mathrm{min}$, and detection was performed at $280 \mathrm{~nm}$. All computational calculations were performed on PCMODEL V 9.0 software. ${ }^{15)}$ The geometry optimizations of the structures leading to energy minima and the conformational analysis were achieved using MMFF force field.

The leaves of Vateria indica LinN. were collected in October 2007 and identified by one of the coauthors (V.C.). A voucher specimen (number DP033) has been deposited in the Gifu Pharmaceutical University.

Dried and ground leaves $(2.0 \mathrm{~kg})$ of $\mathrm{V}$. indica were extracted successively with acetone $(101 \times 24 \mathrm{~h} \times 3), \mathrm{MeOH}(101 \times 24 \mathrm{~h} \times 3)$, and $70 \% \mathrm{MeOH}$ $(101 \times 24 \mathrm{~h} \times 2)$ at $\mathrm{rt}$. The extract was concentrated to yield respective residues; $330 \mathrm{~g}$ (acetone), $178 \mathrm{~g}(\mathrm{MeOH})$, and $57 \mathrm{~g}(70 \% \mathrm{MeOH})$.

The acetone extract $(330 \mathrm{~g})$ was suspended in acetone (11), and the insoluble part recrystallized from methanol- $\mathrm{H}_{2} \mathrm{O}$ to yield $\mathbf{3 6}(5.2 \mathrm{~g})$. The filtrate was subjected to RP column chromatography $(\mathrm{CC})$ on DMS eluted with a mixture of $\mathrm{MeOH}-\mathrm{H}_{2} \mathrm{O}$, decreasing in polarity to give 18 fractions $\left({ }^{\mathrm{A}} \mathrm{Fr}\right.$. $1-$ ${ }^{A}$ Fr. 18). The combined fractions of ${ }^{A}$ Fr. 1 and ${ }^{A}$ Fr. 2 (Fr. A) $\left[\mathrm{H}_{2} \mathrm{O}-\mathrm{MeOH}\right.$ $(9: 1), 50 \mathrm{~g}]$ were further subjected to RP CC on DMS $\left(\mathrm{H}_{2} \mathrm{O}-\mathrm{MeOH}\right.$ gradient system, $0-100 \% \mathrm{MeOH}$ ) to give 20 fractions (Fr. A-1-Fr. A-20). The combined fractions of Fr. A-3 and Fr. A-4 (Fr. A-3.4) were further subjected to $\mathrm{Si}$ gel $\mathrm{CC}$ (EtOAc- $\mathrm{CHCl}_{3}-\mathrm{MeOH}$ gradient system) to give 31 fractions (Fr. A-3.4-1 - Fr. A-3.4-31). Further purification of Fr. A-3.4-5 to Fr. A-3.49 by repeated Sephadex LH-20 CC (MeOH) and RP CC through Sep-Pak cartridges $\left(\mathrm{H}_{2} \mathrm{O}-\mathrm{MeOH}\right.$ gradient system) achieved the isolation of $6(1 \mathrm{mg})$, $\mathbf{1 0}(320 \mathrm{mg}), \mathbf{1 2}(22 \mathrm{mg}), \mathbf{1 4}(500 \mathrm{mg}), \mathbf{1 5}(77 \mathrm{mg}), \mathbf{1 6}(4.8 \mathrm{mg}), \mathbf{1 8}(14 \mathrm{mg})$, $20(800 \mathrm{mg})$, and $27(1.0 \mathrm{~g})$. Fr. A-3.4-14 was purified by Sephadex LH-20 $\mathrm{CC}(\mathrm{MeOH})$ and RP CC through Sep-Pak cartridges $\left(\mathrm{H}_{2} \mathrm{O}-\mathrm{MeOH}\right.$ gradient system) and RP HPLC $\left(\mathrm{H}_{2} \mathrm{O}-\mathrm{MeOH}\right)$ to give 1 (4.2 mg), $2(1.0 \mathrm{~g}), 19$ $(5.2 \mathrm{mg}), \mathbf{2 1}(20 \mathrm{mg}), \mathbf{2 2}(113 \mathrm{mg})$, and $23(4.4 \mathrm{mg})$. Compound $7(38 \mathrm{mg})$, $13(8.0 \mathrm{mg}), \mathbf{3 1}(54 \mathrm{mg})$, and $\mathbf{3 3}(110 \mathrm{mg})$ were obtained from Fr. A-3.4-17 to Fr. A-3.4-21 by Sephadex LH-20 CC (MeOH) and repeated RP CC through Sep-Pak cartridges $\left(\mathrm{H}_{2} \mathrm{O}-\mathrm{MeOH}\right.$ gradient system). Fr. A-3.4-26 was purified by Sephadex LH-20 CC $(\mathrm{MeOH})$, repeated reversed-phase CC through Sep-Pak cartridges $\left(\mathrm{H}_{2} \mathrm{O}-\mathrm{MeOH}\right.$ gradient system) and RP HPLC $\left(\mathrm{H}_{2} \mathrm{O}-\mathrm{MeOH}\right)$ to give $\mathbf{2 8}(46 \mathrm{mg}), \mathbf{2 9}(58 \mathrm{mg})$, and $\mathbf{3 2}(110 \mathrm{mg})$. The combined fractions of ${ }^{\mathrm{A}} \mathrm{Fr} .3-{ }^{\mathrm{A}} \mathrm{Fr}$. 5 (Fr. B) $\left[\mathrm{H}_{2} \mathrm{O}-\mathrm{MeOH}(19: 1\right.$ to $\left.4: 1), 59 \mathrm{~g}\right]$ were further subjected to reversed-phase CC on ODS $\left(\mathrm{H}_{2} \mathrm{O}-\mathrm{MeOH}\right.$ gradient system, $0-100 \% \mathrm{MeOH}$ ) to give 36 fractions (Fr. B-1-Fr. B-36). Purification of Fr. B-5 by $\mathrm{Si}$ gel $\mathrm{CC}$ (EtOAc- $\mathrm{CHCl}_{3}-\mathrm{MeOH}$ gradient system), Sephadex LH-20 CC (MeOH), RP CC through Sep-Pak cartridges $\left(\mathrm{H}_{2} \mathrm{O}-\mathrm{MeOH}\right.$ gradient system), and reversed-phase HPLC $\left(\mathrm{H}_{2} \mathrm{O}-\mathrm{MeOH}\right)$ achieved the isolation of $\mathbf{9}(1.3 \mathrm{mg}), \mathbf{2 5}(4 \mathrm{mg})$, and $\mathbf{2 6}(6.8 \mathrm{mg})$. Fr. B-22 was purified by $\mathrm{Si}$ gel $\mathrm{CC}$ (EtOAc- $\mathrm{CHCl}_{3}-\mathrm{MeOH}$ gradient system), Sephadex LH-20 CC (MeOH), reversed-phase CC through Sep-Pak cartridges $\left(\mathrm{H}_{2} \mathrm{O}-\mathrm{MeOH}\right.$ gradient system), and VLC ( $n$-hexane-acetone) to give $5(11 \mathrm{mg}), \mathbf{3 4}(13 \mathrm{mg})$, and $\mathbf{3 5}(6.4 \mathrm{mg})$. The combined fractions of ${ }^{\mathrm{A}} \mathrm{Fr} .6$ ${ }^{\mathrm{A}} \mathrm{Fr} .10$ (Fr. C) $\left[\mathrm{H}_{2} \mathrm{O}-\mathrm{MeOH}(4: 1\right.$ to $\left.21: 19), 30 \mathrm{~g}\right]$ were further subjected to $\mathrm{Si}$ gel CC (EtOAc- $\mathrm{CHCl}_{3}-\mathrm{MeOH}$ gradient system) to give 22 fractions ( $\mathrm{Fr}$. C-1-Fr. C-22). Repeated RP CC through Sep-Pak cartridges achieved the isolation of $4(1 \mathrm{mg})$.

The $\mathrm{MeOH}$ extract (178g) was subjected to $\mathrm{CC}$ on $\mathrm{Si}$ gel eluted with a mixture (EtOAc- $\mathrm{CHCl}_{3}-\mathrm{MeOH}$ gradient system) to give 20 fractions $\left({ }^{\mathrm{M}} \mathrm{Fr}\right.$. $\left.1{ }^{\mathrm{M}} \mathrm{Fr} .20\right) .{ }^{\mathrm{M}} \mathrm{Fr} .5$ [EtOAc- $\mathrm{CHCl}_{3}-\mathrm{MeOH}(320: 160: 11), 1.5 \mathrm{~g}$ ] was purified by $\mathrm{Si}$ gel $\mathrm{CC}$ (EtOAc- $\mathrm{CHCl}_{3}-\mathrm{MeOH}$ gradient system), RP CC through Sep-Pak cartridges $\left(\mathrm{H}_{2}-\mathrm{MeOH}\right.$ gradient system), and RP HPLC $\left(\mathrm{H}_{2} \mathrm{O}-\right.$ $\mathrm{MeOH})$ to give $\mathbf{1 7}(2.4 \mathrm{mg})$. Compounds $\mathbf{2 4}(1.3 \mathrm{mg})$ and $\mathbf{3 0}(5.0 \mathrm{mg})$ were obtained from ${ }^{\mathrm{M}} \mathrm{Fr} .9$ [EtOAc- $\mathrm{CHCl}_{3}-\mathrm{MeOH}(15: 8: 4), 2.6 \mathrm{~g}$ ] after separation by Sephadex LH-20 CC (MeOH) and RP HPLC $\left(\mathrm{H}_{2} \mathrm{O}-\mathrm{MeOH}\right) .{ }^{\mathrm{M}} \mathrm{Fr} .14$ [EtOAc- $\mathrm{CHCl}_{3}-\mathrm{MeOH}(20: 10: 12), 2.7 \mathrm{~g}$ ] was further purified by Sephadex LH-20 CC (MeOH), VLC [EtOAc-CHCl $-\mathrm{MeOH}(15: 8: 4)]$, and RP CC through Sep-Pak cartridges $\left(\mathrm{H}_{2} \mathrm{O}-\mathrm{MeOH}\right)$ and reversed-phase HPLC $\left(\mathrm{H}_{2} \mathrm{O}-\mathrm{MeOH}\right)$ to obtain $\mathbf{8}(19 \mathrm{mg})$ and $\mathbf{1 1}(4.0 \mathrm{mg})$. Compounds $\mathbf{3}(7.8 \mathrm{mg})$ and $37(6.1 \mathrm{mg})$ were obtained from ${ }^{\mathrm{M}} \mathrm{Fr}$. 16 [EtOAc- $\mathrm{CHCl}_{3}-\mathrm{MeOH}$ $(20: 10: 12), 7.7 \mathrm{~g}]$ after purification by Sephadex LH-20 CC $(\mathrm{MeOH})$, and RP CC through Sep-Pak cartridges $\left(\mathrm{H}_{2} \mathrm{O}-\mathrm{MeOH}\right)$ and RP HPLC $\left(\mathrm{H}_{2} \mathrm{O}-\right.$ $\mathrm{MeOH})$

Compound 1 (Vateriaphenol F): A pale-yellow solid; $[\alpha]_{\mathrm{D}}^{25}-136^{\circ}$ $(c=0.1, \mathrm{MeOH}) ; \mathrm{CD}(c=22.1 \mu \mathrm{M}, \mathrm{MeOH}) \mathrm{nm}(\Delta \varepsilon): 209$ (-248.9), 218 $(+111.9), 238(-113.7), 283(+3.7)$, and $298(-25.2) ; \mathrm{UV}(\mathrm{MeOH}) \lambda_{\max }$ $(\log \varepsilon): 209$ (5.56), $228(5.28), 263(4.80)$, and $285(4.63) \mathrm{nm}$; positive ion ESI-MS $m / z$ : $947.2670[\mathrm{M}+\mathrm{Na}]^{+}\left(\right.$Calcd for $\left.\mathrm{C}_{56} \mathrm{H}_{43} \mathrm{O}_{13} \mathrm{Na}: 947.2674\right) ;{ }^{1} \mathrm{H}-$ and ${ }^{13} \mathrm{C}-\mathrm{NMR}$ spectroscopic data at $-30{ }^{\circ} \mathrm{C}\left[{ }^{1} \mathrm{H}(600 \mathrm{MHz}),{ }^{13} \mathrm{C}(150 \mathrm{MHz})\right.$, acetone- $d_{6}$ ] and HMBC correlations, see Table 1 .

Compound 2 (Vaterioside A): A pale-yellow solid; $[\alpha]_{\mathrm{D}}^{25}-50^{\circ}(c=0.1$, $\mathrm{MeOH}) ; \mathrm{CD}(c=22.1 \mu \mathrm{M}, \mathrm{MeOH}) \mathrm{nm}(\Delta \varepsilon): 220(+2.7), 235(-24.7), 250$ $(+7.1), 253(+6.5), 278(+2.1)$, and $294(-6.6) ; \mathrm{UV}(\mathrm{MeOH}) \lambda_{\max }(\log \varepsilon)$ : 208 (3.52), 228 (5.29), 260 (4.94), 272 (4.62), and 319 (4.43) nm; positive ion ESI-MS $m / z$ : $615.1850[\mathrm{M}+\mathrm{H}]^{+}\left(\right.$Calcd for $\left.\mathrm{C}_{34} \mathrm{H}_{31} \mathrm{O}_{11}: 615.1861\right) ;{ }^{1} \mathrm{H}-$ and ${ }^{13} \mathrm{C}$-NMR spectroscopic data $\left[{ }^{1} \mathrm{H}(400 \mathrm{MHz}),{ }^{13} \mathrm{C}(100 \mathrm{MHz})\right.$, acetone$d_{6}$, see Table 2; HMBC correlations, see Fig. 7. 
Compound 4 (Vaterioside B): A pale-yellow amorphous solid; $[\alpha]_{\mathrm{D}}^{25}$ $-189^{\circ}(c=0.1, \mathrm{MeOH}) ; \mathrm{CD}(c=22.1 \mu \mathrm{M}, \mathrm{MeOH}) \mathrm{nm}(\Delta \varepsilon): 227(-59.0)$, $231(-66.5), 236(-65.2)$, and $289(-37.6)$; UV (MeOH) $\lambda_{\max }(\log \varepsilon): 227$ (4.63) and $284(3.97) \mathrm{nm}$; positive ion ESI-MS $m / z$ : $1091.3065[\mathrm{M}+\mathrm{Na}]^{+}$ (Calcd for $\mathrm{C}_{62} \mathrm{H}_{52} \mathrm{O}_{17} \mathrm{Na}$ : 1091.3097); ${ }^{1} \mathrm{H}$ - and ${ }^{13} \mathrm{C}-\mathrm{NMR}$ spectroscopic data $\left[{ }^{1} \mathrm{H}(400 \mathrm{MHz}),{ }^{13} \mathrm{C}(100 \mathrm{MHz})\right.$, acetone- $\left.d_{6}\right]$ and HMBC correlations, see Table 3 .

Acid Hydrolysis of 4 Compound 4 (2 mg) was refluxed for $6 \mathrm{~h}$ with $5 \%$ $\mathrm{HCl}$. The reaction mixture was extracted with EtOAc to afford 5 (1 mg).

\section{References}

1) Kirtikar K. R., Basu B. D., An I. C. S., "Indian Medicinal Plants," Vol. 1, Dehra Dun, India, Bishen Singh Mahendra Pal Singh, 1991, pp. $281-293$.

2) Grover G. S., Rao J. T., Perfum. Flavor., 7, 15-17 (1982).

3) Ito T., Tanaka T., Nakaya K. i., Iinuma M., Takahashi Y., Naganawa H., Ohyama M., Nakanishi Y., Bastow K. F., Lee K. H., Tetrahedron Lett., 42, 5909-5912 (2001)

4) Ito T., Tanaka T., Inuma M., Nakaya K. i., Takahashi Y., Sawa R., Naganawa H., Chelladurai V., Tetrahedron, 59, 1255-1264 (2003).

5) Ito T., Abe N., Oyama M., Iinuma M., Helv. Chim. Acta, 91, 1989-1998 (2008)

6) Ito T., Abe N., Masuda Y., Nasu M., Oyama M., Sawa R., Takahashi Y., Iinuma M., Helv. Chim. Acta, 92, 195-208 (2009).

7) Nitta T., Arai T., Takamatsu H., Inatomi Y., Murata H., Iinuma M., Tanaka T., Ito T., Asai F., Iliya I., Nakanishi T., Watabe K., J. Health Sci., 48, 273-276 (2002).

8) Zgoda-Pols J. R., Freyer A. J., Killmer L. B., Porter J. R., J. Nat. Prod., 65, 1554-1559 (2002).

9) Ito T., Akao Y., Yi H., Ohguchi K., Matsumoto K., Tanaka T., Iinuma M., Nozawa Y., Carcinogenesis, 24, 1489-1497 (2003).

10) Shibata M. A., Akao Y., Shibata E., Nozawa Y., Ito T., Mishima S., Morimoto J., Otsuki Y., Cancer Chemother. Pharmacol., 60, 681-691 (2007).

11) Seo E.-K., Chai H., Constant H. L., Santisuk T., Reutrakul V., Beecher C. W. W., Farnsworth N. R., Cordell G. A., Pezzuto J. M., Kinghorn A. D., J. Org. Chem., 64, 6976-6983 (1999).

12) Tabata Y., Takano K., Ito T., Iinuma M., Yoshimoto T., Miura H., Kitao Y., Ogawa S., Hori O., Am. J. Physiol., 293, C411-C418 (2007).

13) Kawabata J., Ichikawa S., Kurihara H., Mizutani J., Tetrahedron Lett, 30, 3785-3788 (1989).

14) Ito T., Tanaka T., Iinuma M., Nakaya K., Takahashi Y., Sawa R., Murata J., Darnaedi D., Helv. Chim. Acta, 87, 479-495 (2004).

15) PCMODEL $v$ 9.0, Serena Software, Box 3076, Bloomington, IN 47402-3076.

16) Sultanbawa M. U. S., Surendrakumar S., Wazeer M. I. M., Bladon P., J. Chem. Soc., Chem. Commun., 1981, 1204-1206 (1981).

17) Prasad A. K., Tyagi O. D., Wengel J., Boll P. M., Olsen C. E., Bisht K. S., Singh A., Sarangi A., Kumar R., Jain S. C., Parmer V. S., Phytochemistry, 39, 655-658 (1995).

18) Lemiere G., Gao M., De Groot A., Dommisse R., Lepoivre J., Pieters L., Buss V., J. Chem. Soc., Perkin Trans. 1, 1995, 1775-1779 (1995).

19) Ito T., Abe N., Oyama M., Iinuma M., Tetrahedron Lett., 50, 25162520 (2009).

20) Cichewicz R. H., Kouzi S. A., Hamann M. T., J. Nat. Prod., 63, 2933 (2000).

21) Lins A. P., Felicio J. D., Braggio M. M., Roque L. C., Phytochemistry, 30, $3144-3146$ (1991).

22) Ito T., Tanaka T., Nakaya K. i., Iinuma M., Takahashi Y., Naganawa H., Ohyama M., Nakanishi Y., Bastow K. F., Lee K. H., Tetrahedron, 57, 7309-7321 (2001).

23) Ito T., Tanaka T., Iinuma M., Iliya I., Nakaya K. i., Ali Z., Takahashi
Y., Sawa R., Shirataki Y., Murata J., Tetrahedron, 59, 5347-5363 (2003).

24) Ito T., Furusawa M., Iliya I., Tanaka T., Nakaya K. i., Sawa R., Kubota Y., Takahashi Y., Riswan S., Iinuma M., Tetrahedron Lett., 46, 3111 3114 (2005).

25) Ito T., Ali Z., Furusawa M., Iliya I., Tanaka T., Nakaya K., Murata J., Darnaedi D., Oyama M., Iinuma M., Chem. Biodivers., 2, 1200-1216 (2005).

26) Fujii F., He Y.-H., Terashima K., Takaya Y., Niwa M., Heterocycles, 65, 2461-2469 (2005)

27) Coggon P., Janes N. F., King F. E., King T. J., Molyneux R. J., Morgan J. W. W., Sellars K., J. Chem. Soc., 1965, 406-409 (1965).

28) Kawabata J., Fukushi E., Mizutani J., J. Am. Chem. Soc., 114, $1115-$ 1117 (1992).

29) Yao C.-S., Lin M., Wang Y.-H., Chin. J. Chem., 22, 1350-1355 (2004).

30) Tanaka T., Ito T., Ido Y., Nakaya K., Iinuma M., Chelladurai V., Chem. Pharm. Bull., 49, 785-787 (2001).

31) Baderschneider B., Winterhalter P., J. Agric. Food Chem., 48, 26812686 (2000).

32) Kim H. J., Chang E. J., Bae S. J., Shim S. M., Park H. D., Rhee C. H., Park J. H., Choi S. W., Arch. Pharm. Res., 25, 293-299 (2002).

33) Ito T., Ali Z., Iliya I., Furusawa M., Tanaka T., Nakaya K., Takahashi Y., Sawa R., Murata J., Darnaedi D., Iinuma M., Helv. Chim. Acta, 88, 23-34 (2005).

34) Diyasena M. N. C., Sotheeswaran S., Surendrakumar S., Balasubramanian S., Bokel M., Kraus W., J. Chem. Soc., Perkin Trans. 1, 1985, 1807-1809 (1985)

35) Matsuda H., Asao Y., Nakamura S., Hamao M., Sugimoto S., Hongo M., Pongpiriyadacha Y., Yoshikawa M., Chem. Pharm. Bull., 57, 487-494 (2009).

36) Dai J. R., Hallock Y. F., Cardellina J. H. 2nd, Boyd M. R., J. Nat. Prod., 61, 351-353 (1998).

37) Oshima Y., Ueno Y., Hisamichi K., Takeshita M., Tetrahedron, 49, 5801-5804 (1993)

38) Tanaka T., Ito T., Nakaya K., Iinuma M., Riswan S., Phytochemistry, 54, 63-69 (2000).

39) Tanaka T., Ito T., Nakaya K., Iinuma M., Takahashi Y., Naganawa H., Riswan S., Heterocycles, 55, 729-740 (2001).

40) Yamada M., Hayashi K., Hayashi H., Tsuji R., Kakumoto K., Ikeda S., Hoshino T., Tsutsui K., Tsutsui K., Ito T., Iinuma M., Nozaki H., Chem. Pharm. Bull., 54, 354-358 (2006).

41) Ohyama M., Tanaka T., Iinuma M., Burandt C. L., Chem. Pharm. Bull., 46, 663-668 (1998).

42) Ito T., Tanaka T., Ido Y., Nakaya K., Iinuma M., Takahashi Y., Naganawa H., Riswan S., Heterocycles, 55, 557-567 (2001).

43) Ito T., Iliya I., Tanaka T., Nakaya K., Akao Y., Nozawa Y., Murata J., Darnaedi D., Iinuma M., Heterocycles, 65, 173-179 (2005).

44) Ahmed A. A., Mabry T. J., Matlin S. A., Phytochemistry, 28, 17511753 (1989).

45) Markham K. R., Ternai B., Stanley R., Geiger H., Mabry T. J., Tetrahedron, 34, 1389-1397 (1978).

46) Itokawa H., Mizuno K., Ichihara Y. and Takeya K., Planta Med., 53, $271-273$ (1987).

47) Zakaria M. B., Saito I., Yao X., Wang R., Matsuura T., Planta Med., 55, 477-478 (1989).

48) Munkombwe N. M., Galebotswe P., Modibesane K., Morebodi N., Phytochemistry, 64, 1401-1404 (2003).

49) Bagchi D., "Resveratrol and Human Health," Keats Publishing, Los Angeles, 2000.

50) Abe K., Sakai K., Uchida M., Gen. Pharmacol., 11, 361-368 (1980).

51) Achenbach H., Hemrich H., Phytochemistry, 30, $1957-1962$ (1991). 